\title{
Development of a lauric acid/albumin hybrid iron oxide nanoparticle system with improved biocompatibility
}

This article was published in the following Dove Press journal:

International Journal of Nanomedicine

20 October 2014

Number of times this article has been viewed

\author{
Jan Zaloga' \\ Christina Janko' \\ Johannes Nowak ${ }^{2}$ \\ Jasmin Matuszak' \\ Sabine Knaup' \\ Dietmar Eberbeck ${ }^{3}$ \\ Rainer Tietze \\ Harald Unterweger' \\ Ralf P Friedrich' \\ Stephan Duerr' \\ Ralph Heimke-Brinck ${ }^{4}$ \\ Eva Baum ${ }^{4}$ \\ Iwona Cicha' \\ Frank Dörje ${ }^{4}$ \\ Stefan Odenbach ${ }^{2}$ \\ Stefan Lyer' \\ Geoffrey Lee ${ }^{5}$ \\ Christoph Alexiou' \\ 'Department of Otorhinolaryngology, \\ Head and Neck Surgery, Section \\ for Experimental Oncology \\ and Nanomedicine (SEON), \\ Else Kröner-Fresenius-Stiftung- \\ Professorship, University Hospital \\ Erlangen, Erlangen, Germany; \\ ${ }^{2}$ Measuring and Automation \\ Technology, Technical University \\ Dresden, Dresden, Germany; \\ ${ }^{3}$ Physikalisch-Technische- \\ Bundesanstalt, Berlin, Germany \\ ${ }^{4}$ Pharmacy Department, University \\ Hospital Erlangen, Erlangen, Germany; \\ ${ }^{5}$ Division of Pharmaceutics, Friedrich \\ Alexander University Erlangen- \\ Nuremberg, Erlangen, Germany
}

Correspondence: Christoph Alexiou Department of Otorhinolaryngology,

Head and Neck Surgery, Section

for Experimental Oncology and

Nanomedicine (SEON), Glueckstraße

I0a, 91054 Erlangen, Germany

$\mathrm{Tel}+4991318534769$

Fax +49913 I8534828

Email c.alexiou@web.de
Abstract: The promising potential of superparamagnetic iron oxide nanoparticles (SPIONs) in various nanomedical applications has been frequently reported. However, although many different synthesis methods, coatings, and functionalization techniques have been described, not many core-shell SPION drug delivery systems are available for clinicians at the moment. Here, bovine serum albumin was adsorbed onto lauric acid-stabilized SPIONs. The agglomeration behavior, zeta potential, and their dependence on the synthesis conditions were characterized with dynamic light scattering. The existence and composition of the core-shell-matrix structure was investigated by transmission electron microscopy, Fourier transform infrared spectroscopy, and zeta potential measurements. We showed that the iron oxide cores form agglomerates in the range of $80 \mathrm{~nm}$. Moreover, despite their remarkably low tendency to aggregate even in a complex media like whole blood, the SPIONs still maintained their magnetic properties and were well attractable with a magnet. The magnetic properties were quantified by vibrating sample magnetometry and a superconducting quantum interference device. Using flow cytometry, we further investigated the effects of the different types of nanoparticle coating on morphology, viability, and DNA integrity of Jurkat cells. We showed that by addition of bovine serum albumin, the toxicity of nanoparticles is greatly reduced. We also investigated the effect of the particles on the growth of primary human endothelial cells to further demonstrate the biocompatibility of the particles. As proof of principle, we showed that the hybrid-coated particles are able to carry payloads of up to $800 \mu \mathrm{g} / \mathrm{mL}$ of the cytostatic drug mitoxantrone while still staying colloidally stable. The drug-loaded system exhibited excellent therapeutic potential in vitro, exceeding that of free mitoxantrone. In conclusion, we have synthesized a biocompatible ferrofluid that shows great potential for clinical application. The synthesis is straightforward and reproducible and thus easily translatable into a good manufacturing practice environment.

Keywords: iron oxide nanoparticles, drug delivery, protein corona, magnetic drug targeting, colloidal stability

\section{Introduction}

Superparamagnetic iron oxide nanoparticles (SPIONs) have received increasing attention in recent nanomedical science. These particles, which usually consist of iron oxide cores of 5-20 $\mathrm{nm}$ in diameter and appropriate coatings, have been used for medical applications such as tissue engineering, drug delivery, hyperthermia, and enhanced resolution magnetic resonance imaging techniques. ${ }^{1,2}$ Although many different synthesis methods, coatings, and functionalization techniques have already been described, ${ }^{1,3}$ not many core-shell SPION systems are available for clinicians at the moment. The requirements for these systems are high. The ideal core-shell nanoparticle system for biomedical applications is colloidally stable, even in a complex media like 
whole blood, while it retains its magnetic properties. ${ }^{4}$ The size of the particle aggregates should be controllable by the synthesis and lie between $30 \mathrm{~nm}$ and $200 \mathrm{~nm}$, as this greatly enhances their endocytic uptake by cells and their enrichment in tumor tissues. Above $200 \mathrm{~nm}$, their ability to penetrate into tissues decreases drastically. Also, nanoparticles larger than $200 \mathrm{~nm}$ are more likely to be taken up by macrophages by phagocytosis, which results in rapid clearance via the reticuloendothelial system. ${ }^{5,6}$ By their coating, such nanoparticle systems should also be able to overcome the intrinsic toxicity of naked SPIONs. ${ }^{7}$ For optimal cellular uptake, the surface charge of the nanoparticles should ideally be slightly positive or neutral, as highly negative charges hinder cellular uptake. ${ }^{2,5,8,9}$ However, this often provides a major obstacle for electrostatically stabilized ferrofluids. ${ }^{10}$ From the Derjaguin-Landau-Verwey-Overbeek theory on the electrostatic stabilization mechanism of such lyophobic colloids ${ }^{11}$ it follows that low absolute charges promote aggregation and precipitation. Thus, high positive or negative charges are desirable from this point of view. On the contrary, particles with high positive surface charges have shown increased toxicity before. ${ }^{6}$ Finally, to make the step from experimental into up-scaled production following good manufacturing practice guidelines is necessary for clinical trials, the synthesis has to be straightforward, reproducible, and capable of producing products in larger volumes.

The primary coating of SPIONs with surfactants such as fatty acids is a well-known method to produce relatively stable, primary ferrofluids. ${ }^{12}$ However, the stability of these colloids in biorelevant media is questionable, as it depends on low ionic strength of the solution, alkaline $\mathrm{pH}$, and the constant presence of an excess of the surfactant. ${ }^{13}$ In our previous work, we have shown that lauric acid-coated SPIONs still have outstanding potential for magnetic drug targeting (MDT) ${ }^{14}$ In MDT, SPIONs are injected into a blood vessel and are then accumulated locally using a magnetic field. This method is particularly useful for targeting of solid tumors. Thus, local concentrations of carrier system and drug are greatly enhanced as compared with intravenous injection, where the compounds are distributed in the whole body. ${ }^{15}$ Therefore, it seems evident that the systems used for this purpose need to have high toxic thresholds. Also, local accumulation of SPION colloids with magnets can lead to enhanced agglomeration. High colloidal stability and redispersibility after agglomeration are therefore essential parameters for those ferrofluids. Recently, the protein corona of nanoparticles and its contribution to colloidal stability and cellular uptake has been frequently discussed. ${ }^{16,17}$
The adsorption of fatty acids onto albumin is a well-known effect. ${ }^{18}$ The working hypothesis in this paper was that, if formed under defined chemical conditions, an artificial protein coating should increase the colloidal stability of the lauric acid-coated SPIONs. It should also decrease the intrinsic toxicity while hopefully retaining the magnetic properties of the particle system. Ideally, the particles should exhibit a core-shell structure, with the surfactant still remaining on the surface and the protein shell on the outside. For this purpose, we developed a SPION system that exhibits all the aforementioned properties and proved its suitability for magnetic drug delivery as a proof of principle for one of the many potential biomedical applications.

\section{Materials and methods Materials}

Iron (II) chloride tetrahydrate $\left(\mathrm{FeCl}_{2} \cdot 4 \mathrm{H}_{2} \mathrm{O}\right)$, hydroxylammonium chloride, bovine serum albumin (BSA), and Eppendorf ultrafiltration tubes with a molecular weight cutoff (MWCO) of $3 \mathrm{kDa}$ were purchased from Merck (Darmstadt, Germany). Iron (III) chloride hexahydrate $\left(\mathrm{FeCl}_{3} \cdot 6 \mathrm{H}_{2} \mathrm{O}\right)$, dialysis tubes (Spectrapor 6, MWCO $8 \mathrm{kDa}$ ), ammonium chloride, formic acid, hydrochloric acid 25\%, and ammonia solution 25\% were supplied by Roth (Karlsruhe, Germany). Propidium iodide (PI), sodium citrate, triton X-100, ammonium formate, lauric acid, and acetone were purchased from Sigma-Aldrich (St Louis, MO, USA). Sulfosalycylic acid solution 20\% was bought from Applichem (Darmstadt, Germany). Mitoxantrone (MTO) solution $(2 \mathrm{mg} / \mathrm{mL})$ was purchased from TEVA Pharma (Ulm, Germany). Ringer's solution was bought from Baxter Healthcare (Zurich, Switzerland). Falcon ultrafiltration tubes (MWCO $100 \mathrm{kDa}$ ) were purchased from Sartorius (Goettingen, Germany). Recombinant chicken Annexin A5 (AxA5; responsif GmbH, Erlangen, Germany) was labeled with fluorescein isothiocyanate (AxA5-FITC) according to the manufacturer's instructions (Sigma-Aldrich). Hoechst 33342 (Hoe) and DiIC $_{1}$ (5) (hexamethylindodicarbocyanine iodide dye [DiI]) were purchased from Thermo Fisher Scientific (Waltham, MA, USA).

\section{Synthesis of in situ-coated lauric acid ferrofluid (SEON $\left.{ }^{L A}\right)$}

Lauric acid-coated magnetite nanoparticles were synthesized by coprecipitation and subsequent in situ coating with lauric acid, a variation of the process described by Bica et al. ${ }^{12}$ Briefly, Fe (II) and Fe (III) salts $\left(1.988 \mathrm{~g}\right.$ of $\mathrm{FeCl}_{2} \cdot 4 \mathrm{H}_{2} \mathrm{O}$ and $5.406 \mathrm{~g}$ of $\mathrm{FeCl}_{3} \cdot 6 \mathrm{H}_{2} \mathrm{O}$ ) were dissolved in $20 \mathrm{~mL}$ of Millipore water (Merck Millipore, Billerica, MA, USA) and 
stirred at $80^{\circ} \mathrm{C}$ under an argon atmosphere. Under vigorous stirring, $20 \mathrm{~mL}$ of $\mathrm{NH}_{3}$ solution (23\%) was then added. Immediately, the solution was heated to $90^{\circ} \mathrm{C}$ and $1.25 \mathrm{~g}$ lauric acid, dissolved in acetone, was added. The blackish precipitate quickly formed a colloidal, brownish suspension, which was left to homogenize for 30 minutes at $90^{\circ} \mathrm{C}$. The fluid was then placed inside a dialysis tube with a MWCO of $8 \mathrm{kDa}$ and dialyzed multiple times. The so-prepared suspension was still colloidally stable and was diluted to $100 \mathrm{~mL}$ with Millipore water.

\section{Synthesis of lauric acid/BSA hybrid nanoparticles SEON ${ }^{\text {LA-BSA }}$ and coupling of MTO}

The total iron concentration of the SEON ${ }^{\mathrm{LA}}$ was determined with a previously described photometric method. ${ }^{19}$ The particles were diluted 1:100 and dissolved in $\mathrm{HCl}$ at $90^{\circ} \mathrm{C}$. After cooling to room temperature, hydroxylammonium chloride solution $10 \%$, sulfosalicylic acid, and $\mathrm{NH}_{3}$ were added. The iron content was then determined by measuring the ultraviolet (UV) absorbance at $405 \mathrm{~nm}$ with a microplate reader (Filtermax F5; Molecular Devices, Sunnyvale, CA, USA). In the reaction mixture, the required amount of $20 \% \mathrm{BSA}$ stock solution was diluted to the final volume of $20 \mathrm{~mL}$. In our experiments, we used BSA resulting in final protein concentrations of $1 \%-10 \%$ (wt/vol $\%$ ). Under vigorous stirring, the SEON ${ }^{\mathrm{LA}}$ suspension was added dropwise to the diluted BSA to form SEON ${ }^{\mathrm{LA}-\mathrm{BSA}}$ with a total iron concentration of around $2.5 \mathrm{mg} / \mathrm{mL}$. The reaction mixture was stirred for 10 minutes and ultrafiltrated (MWCO $100 \mathrm{kDa}, 4,000 \times g$, 20 minutes) in a 5430R Eppendorf centrifuge (Hamburg, Germany). The $\mathrm{pH}$ of the final solution was 7.0. After sterile filtration through a $0.22 \mu \mathrm{m}$ syringe filter, the iron concentrations were measured again and adjusted to $2.33 \mathrm{mg} / \mathrm{mL}$. The synthesis was also performed without any BSA (just dilution with water) to get a comparable $\mathrm{SEON}^{\mathrm{LA}}$ product. This product was sterilized by autoclaving $\left(121^{\circ} \mathrm{C}, 20\right.$ minutes $)$.

To bind MTO to the particles, $1 \mathrm{~mL}$ of sterile $6 \%$ SEON ${ }^{\mathrm{LA}-\mathrm{BSA}}$ was vortexed with the appropriate amount of drug stock solution $(2 \mathrm{mg} / \mathrm{mL})$ for 1 minute and then left to incubate for another 15 minutes at room temperature. To determine the binding efficiency, $500 \mu \mathrm{L}$ of the resulting mixture was filtered through a 3,000 Da MWCO filter for 20 minutes with an Eppendorf Minispin plus centrifuge $(14,000 \times g)$. We confirmed that free MTO, but not the particles or the protein, can pass through this membrane (data not shown). The amount of unbound drug only was determined from the ultrafiltrate using an established high-performance liquid chromatography-UV method as described previously. ${ }^{20}$
For cell culture experiments, $300 \mu \mathrm{g}$ of MTO was loaded onto $1 \mathrm{~mL}$ of $6 \% \mathrm{SEON}^{\mathrm{LA}-\mathrm{BSA}}$ to form SEON ${ }^{\mathrm{LA}-\mathrm{BSA} * \text { MTO }}$. For Fourier transform infrared spectroscopy (FTIR) measurements, we used 6\% SEON ${ }^{\mathrm{LA}-\mathrm{BSA}}$, SEON ${ }^{\mathrm{LA}}$, and $4 \%$ SEON ${ }^{\mathrm{LA}-\mathrm{BSA}}$, which were ultrafiltrated ten times (MWCO $100 \mathrm{kDa})$. For all other experiments, $6 \% \mathrm{SEON}^{\mathrm{LA}-\mathrm{BSA}}$ or SEON ${ }^{\mathrm{LA}}$ were used.

\section{Dynamic light scattering measurements of size and zeta potential}

Size measurements were performed with a MALVERN Zetasizer Nano ZS (Malvern Instruments, Malvern, UK) and a Nanophox (Sympatec, Clausthal-Zellerfeld, Germany). The respective suspensions were diluted to a total iron concentration of $25 \mu \mathrm{g} / \mathrm{mL}$ with Millipore water or Roswell Park Memorial Institute (RPMI) 1640 media and measured in triplicate in backscattering or cross-correlation mode.

The zeta potential was determined with a NICOMP 380ZLS (Nicomp, Port Richey, FL, USA) using the Smoluchowski equation. The suspensions were diluted to a total iron concentration of $25 \mu \mathrm{g} / \mathrm{mL}$ in Millipore water, RPMI 1640 media, or ammonium formate buffer $100 \mathrm{mM}$, and the rectangular scattering was measured.

\section{$\mathrm{pH}$ dependence of the zeta potential $(\zeta)$ of the colloid}

Six percent of SEON ${ }^{\mathrm{LA}-\mathrm{BSA}}$ was diluted to a total iron concentration of $25 \mu \mathrm{g} / \mathrm{mL}$ with ammonium formate buffer $(100 \mathrm{mM})$ adjusted to different $\mathrm{pH}$ values between 3 and 9. The zeta potential was determined with a NICOMP 380ZLS at an E-field strength of $0.5 \mathrm{~V} / \mathrm{cm}$ using the Smoluchowski equation.

\section{Transmission electron microscopy}

Pictures were taken with a CM 300 UltraTWIN (Philips, Eindhoven, Netherlands) operated at an acceleration voltage of $300 \mathrm{kV}$. Samples were prepared by drying $10 \mu \mathrm{L}$ of diluted nanoparticle suspension on a carbon-coated Athene S147-2 copper grid (Plano, Wetzlar, Germany). Images were obtained with a charge-coupled device camera; for determination of the size distribution of the iron oxide cores, the software ImageJ 1.47 was used.

\section{FTIR measurements}

We compared SEON ${ }^{\mathrm{LA}}, 6 \% \mathrm{SEON}^{\mathrm{LA}-\mathrm{BSA}}$, and 4\% SEON ${ }^{\mathrm{LA}-\mathrm{BSA}}$ after multiple ultrafiltration with FTIR. Three milliliters of the respective fluid was frozen in $\mathrm{a}-80^{\circ} \mathrm{C}$ freezer and then freeze-dried overnight. FTIR spectra of the lyophilized samples were then taken with a BRUKER Alpha FTIR 
spectrometer operated in attenuated total reflection mode from $4,000 \mathrm{~cm}^{-1}$ to $400 \mathrm{~cm}^{-1}$ with a step size of $0.5 \mathrm{~cm}^{-1}$.

\section{Magnetization measurements} Vibrating sample magnetometry

The magnetization curves were measured using the vibrating sample magnetometer (VSM) Lake Shore 7,407 (LakeShoreCryotronix Inc., Westerville, OH, USA). The external magnetic field was constantly increased while the magnetization of the sample was measured. The resulting magnetization curves allow for the calculation of the saturation magnetization $M_{\mathrm{S}}$ leading to the volume fraction of magnetic material $\Phi$, as the spontaneous magnetization of the core material, which is assumed as magnetite here, is known.

\section{Superconducting quantum interference device susceptometry}

Alternatively, a superconducting quantum interference device (SQUID)-based susceptometer magnetic property measurement system (Quantum Design, San Diego, CA, USA) was used for the measurement of the magnetization in external magnetic fields up to $5 \mathrm{~T}$. For the measurements, $0.075 \mathrm{~mL}$ of the SPION samples was filled in polycarbonate capsules. Additionally, the signal of the empty capsule was measured and subtracted from the sample's raw data within the measurement device. The diamagnetic susceptibility of the dispersion medium, demineralized water, was subtracted afterward. Thus, the obtained $\mathrm{M}(\mathrm{H})$ curves represent the magnetization of the particles only.

\section{Whole blood assays}

$\mathrm{SEON}^{\mathrm{LA}}$ and $6 \% \mathrm{SEON}^{\mathrm{LA}-\mathrm{BSA}}$ particle suspensions were diluted in freshly extracted, ethylenediaminetetraacetic acidstabilized human whole blood to an iron concentration of $1 \mathrm{mg} / \mathrm{mL}$. Images of the vials were taken after 5 minutes and 60 minutes. After 30 minutes, $1 \mu \mathrm{L}$ of the respective blood sample was placed on a glass slide and investigated with a Zeiss Axio observer Z1 microscope (Zeiss Optics, Jena, Germany). After 24 hours of incubation, the SEON ${ }^{\mathrm{LA}-\mathrm{BSA}}$ sample was centrifuged at $4^{\circ} \mathrm{C}$ and $300 \times g$ to separate the particle-containing suspension from the cellular compounds. The supernatant was diluted and then investigated with transmission electron microscopy (TEM) under the same conditions as the other samples.

\section{Release kinetics of SEON ${ }^{L A-B S A * M T O}$}

To investigate the release behavior of MTO from the synthesized particle system, we used the dialysis method.
Five milliliters of SEON ${ }^{\mathrm{LA}-\mathrm{BSA} * \mathrm{MTO}}$ was put in a dialysis bag with a MWCO of $8 \mathrm{kDa}$. It was incubated in phosphate-buffered saline (PBS) at $37^{\circ} \mathrm{C}$ under gentle shaking for 72 hours. After defined time points, three samples (volume $=0.5 \mathrm{~mL}$ ) were taken from the incubation solution and the same amount of fresh PBS was added. The amount of free MTO was determined by high-performance liquid chromatography-UV. After 72 hours, an aliquot of the remaining ferrofluid inside the dialysis bag was hydrolyzed using hydrochloric acid at $95^{\circ} \mathrm{C}$ for 20 minutes and unreleased MTO was determined from the lysate. As control SEON ${ }^{\mathrm{LA}-\mathrm{BSA} * \mathrm{MTO}}$ was hydrolyzed, the total amount of MTO was determined from the lysate and used as the $100 \%$ reference.

\section{In vitro toxicity}

\section{Cells and culture conditions}

Jurkat cells, a non-adherent human T-cell leukemia cell line (clone number DSMZ ACC 282), were cultured at $37^{\circ} \mathrm{C}$ and $5 \% \mathrm{CO}_{2}$ in RPMI 1640 medium supplemented with $10 \%$ fetal calf serum (FCS), $1 \%$ glutamine, $1 \%$ penicillin-streptomycin (all from Thermo Fisher), and 1\% HEPES (10 mM, pH 7.2) (Merck KGaA, Darmstadt, Germany).

Human umbilical vein endothelial cells (HUVECs) were isolated from freshly collected umbilical cords using an established technique. Cells were cultured in endothelial cell growth medium (PromoCell, Heidelberg, Germany) with endothelial cell growth supplement containing $5 \%$ $\mathrm{FCS}, 4 \mu \mathrm{g} / \mathrm{mL}$ heparin, $10 \mathrm{ng} / \mathrm{mL}$ epidermal growth factor, $1 \mu \mathrm{g} / \mathrm{mL}$ hydrocortisone, $50 \mu \mathrm{g} / \mathrm{mL}$ gentamycin sulfate, and $50 \mathrm{ng} / \mathrm{mL}$ amphotericin $\mathrm{B}$, at humidified $5 \% \mathrm{CO}_{2}$ atmosphere. In all experiments, HUVECs at passage 1 were used.

Statistical significance analyses were performed using Student's $t$-test in MS Excel $\left({ }^{*} P<0.05,{ }^{*} P<0.005\right.$, $* * * P<0.0005)$.

\section{Determination of SEON ${ }^{L A-B S A}$ toxicity on primary endothelial cells}

For monitoring the effects of nanoparticles on HUVEC viability, the xCELLigence system (RTCA DP Analyzer; Roche Diagnostics, Mannheim, Germany) was used. The system was placed in a humidified incubator at $37^{\circ} \mathrm{C}$ and $5 \% \mathrm{CO}_{2}$. Experiments were performed in 16-well E-plates (ACEA Bioscience, San Diego, USA), in which the impedance is measured with the help of microelectrodes localized at the bottom of the wells. For the background measurement, $100 \mu \mathrm{L}$ of cell-free endothelial cell growth medium was added to the wells. Afterward, $50 \mu \mathrm{L}$ of media from each well was replaced with $50 \mu \mathrm{L}$ of cell suspension 
containing $1 \times 10^{3}$ HUVECs. Experiments were performed in hexaplicates.

About 30 minutes after seeding of the cells, the monitoring of impedance by the xCELLigence system was started. Twenty-four hours after seeding, $100 \mu \mathrm{L}$ of medium containing different concentrations of nanoparticles was added. From the impedance, the system calculates the so-called "cell-index". This dimensionless parameter reflecting the numbers, adherence, and viability of cells was monitored every 10 minutes for 72 hours. In parallel, pure nanoparticle solutions diluted to total iron concentrations of $1 \mu \mathrm{g} / \mathrm{mL}$, $10 \mu \mathrm{g} / \mathrm{mL}$, and $100 \mu \mathrm{g} / \mathrm{mL}$ in cell media were investigated for 72 hours to investigate their effect on the cell-index.

\section{Comparison of SEON ${ }^{L A}$ and SEON ${ }^{L A-B S A}$ toxicity on Jurkat cells}

For solid nanoparticle suspensions, classical cytotoxicity assays in plate photometry that rely on UV absorption or fluorescence have been reported to be misleading. ${ }^{21}$ Here, flow cytometry provides a good alternative because it offers the possibility to analyze the particles separately from the cells. Before every experiment, the viability of the Jurkat cells was confirmed using a MUSE Cell Analyzer (Merck Millipore). When the cell viability exceeded $90 \%$, we proceeded with further experiments.

For all cell experiments, we used the SEON ${ }^{\mathrm{LA}}$ and $6 \%$ SEON $^{\mathrm{LA}-\mathrm{BSA}}$. For the experiments, the cells were counted and adjusted to a density of $2 \times 10^{5}$ cells $/ \mathrm{mL}$ in cell culture media. One milliliter of the cell suspensions was seeded into 48-well plates (Greiner Bioone, Frickenhausen, Germany) and the respective particle amounts were added and cells were incubated at $37^{\circ} \mathrm{C}$. After 24 and 48 hours, $50 \mu \mathrm{L}$ aliquots of the cell suspensions were taken and stained: analysis of phosphatidylserine exposure, plasma membrane integrity, and mitochondrial membrane potential was performed as previously reported by Munoz et al. ${ }^{22}$ In brief, $250 \mu \mathrm{L}$ of a mixture of PI $20 \mu \mathrm{g} / \mathrm{mL}$, DiI $10 \mathrm{nM}$, Hoechst $333421 \mu \mathrm{g} / \mathrm{mL}$, and $0.5 \mu \mathrm{g} / \mathrm{mL}$ fluorescein isothiocyanate-labeled AxA5 in Ringer's solution was added to one of the aliquots, incubated for 20 minutes at $4^{\circ} \mathrm{C}$, and subsequently, measured with a Gallios flow cytometer (Beckman Coulter, Fullerton, CA, USA). Every tube was measured for 60 seconds, thus we received 1,000-3,000 cell counts per measurement depending on the cytotoxicity of the nanoparticles. Electronic compensation was used to eliminate bleed through fluorescence. The forward scatter and side scatter (SSC) were also considered for morphological analysis of the cells. Data analysis was performed with Kaluza software version 2.0 (Beckman Coulter).
Cell cycle and DNA degradation were examined by propidium iodide-triton (PIT) staining according to the protocol of Nicoletti et al. ${ }^{23}$ Briefly, $400 \mu \mathrm{L}$ of a solution containing $0.1 \%$ sodium citrate, $0.1 \%$ Triton X-100, and $50 \mu \mathrm{g} / \mathrm{mL}$ PI was added to another $50 \mu \mathrm{L}$ aliquot of cells, incubated overnight at $4^{\circ} \mathrm{C}$ in the dark, and nuclear fluorescence was measured in flow cytometry.

In parallel, MTO fluorescence was determined using the inherent fluorescence of the drug at wavelengths of $638 \mathrm{~nm}$ (excitation) and $725 \pm 10 \mathrm{~nm}$ (emission).

\section{Investigation of in vitro therapeutic efficiency of SEON ${ }^{L A-B S A * M T O}$ on Jurkat cells}

To investigate the toxicity of SEON ${ }^{\mathrm{LA}-\mathrm{BSA} * \text { MTO }}$, we first diluted the colloid to final MTO concentrations from $0.025 \mu \mathrm{g} / \mathrm{mL}$ to $0.1 \mu \mathrm{g} / \mathrm{mL}$ with cell culture media. The respective amounts of SPIONs were added to the Jurkat cell suspensions $\left(2 \times 10^{5}\right.$ cells $\left./ \mathrm{mL}\right)$ and incubated for 48 hours at $37^{\circ} \mathrm{C}$. Pure MTO and $6 \%$ SEON ${ }^{\mathrm{LA}-\mathrm{BSA}}$ of the same iron concentration were used as controls. Analyses of cell count, viability, and cell cycle were performed after 24 and 48 hours of incubation using flow cytometry as described.

\section{Results}

\section{Size and zeta potential greatly depend on the amount of BSA}

We first investigated the influence of the amount of added protein on the size of the clusters in order to assess the effect on particle stability. Below $0.5 \%$ BSA, the synthesis did not produce stable colloids. At higher BSA concentrations, the mean size ( $Z$-average) of the particles first increased until $1 \%$ BSA. At concentrations of $2 \%$ and above, the mean particle diameter started to decrease again and reached stable values of around $80 \mathrm{~nm}$ in diameter at and above 5\% BSA. The polydispersity index decreased accordingly. Above $5 \%$ final BSA concentration, we did not observe any major changes in size and polydispersity (Figure 1). These findings were also consistent with the sterilization experiments, as suspensions synthesized at protein concentrations of $3 \%$ BSA and below could not be filtered through a $0.22 \mu \mathrm{m}$ filter. Ten percent of aqueous BSA solution or RPMI 1640 media with $10 \%$ FCS did not produce a suitable count rate for dynamic light scattering or zeta potential measurements when diluted in water. The hydrodynamic sizes and zeta potentials of SEON ${ }^{\mathrm{LA}}, 6 \%$ SEON ${ }^{\mathrm{LA}-\mathrm{BSA}}$, and SEON ${ }^{\mathrm{LA}-\mathrm{BSA} * \mathrm{MTO}}$ were also measured in cell culture media (RPMI 1640 with $10 \%$ FCS) after sterilization (Table 1). 
A

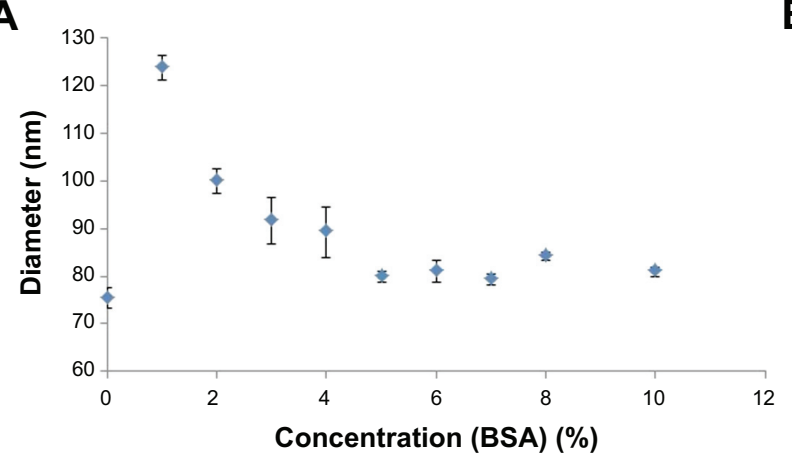

B

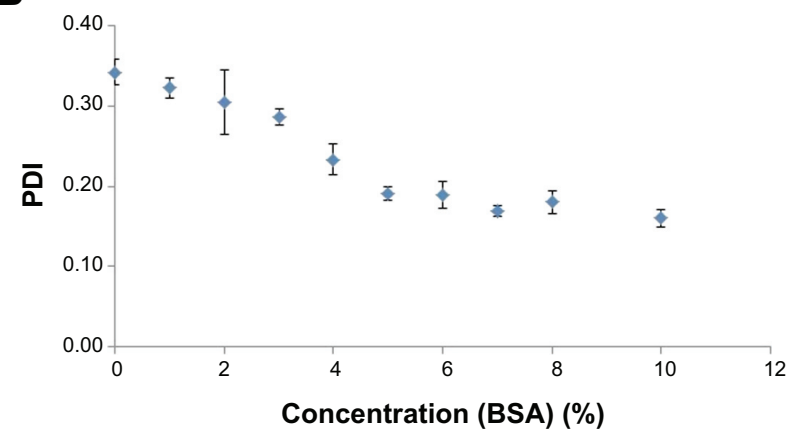

Figure I (A) Aggregate size by volume (Z-average) and (B) polydispersity index of the aggregates depending on the amount of protein ( $\mathrm{n}=3$ ) Abbreviations: PDI, polydispersity index; BSA, bovine serum albumin.

The zeta potential when measured in pure water decreases upon BSA addition and reaches values below $-40 \mathrm{mV}$ above $5 \%$ BSA (Figure 2).

\section{MTO can easily be coupled} to the particles

For SEON ${ }^{\mathrm{LA}-\mathrm{BSA}}$, we observed a maximum loading capacity of up to $800 \mu \mathrm{g} / \mathrm{mL}$ of MTO. Above this payload, the amount of unbound MTO in the supernatant increases in a linear way (Figure S1). The colloids, however, were still stable and not separable from the solvent by centrifugation.

At the chosen payload of $300 \mu \mathrm{g} / \mathrm{mL}$, we found a drug binding efficiency of $99.93 \% \pm 0.01 \%$, which equals a payload of $299.7 \pm 0.035 \mu \mathrm{g} / \mathrm{mL}$ MTO for the SEON ${ }^{\mathrm{LA}-\mathrm{BSA} * \mathrm{MTO}}$.

\section{TEM confirms the core-shell-matrix structure}

The mean core diameter of the SEON ${ }^{\mathrm{LA}-\mathrm{BSA}}$ was $7.64 \pm 1.68 \mathrm{~nm}$, calculated from $n=50$ single cores as depicted in Figure 3A. In the TEM images, the formation of multicore clusters of particles was observed. Although the clusters seen at lower magnifications (Figure 3B) could also be artifacts formed

Table I Particle sizes (volume mean diameter) and zeta potentials of SEON ${ }^{L A}, 6 \%$ SEON ${ }^{L A-B S A}$, and SEON ${ }^{L A-B S A * M T O}$ in RPMI 1640 media supplemented with $10 \%$ FCS

\begin{tabular}{|c|c|c|}
\hline & $\begin{array}{l}\text { Hydrodynamic diameter } \\
\text { by volume }(\mathrm{nm})\end{array}$ & $\zeta(\mathrm{mV})$ \\
\hline SEON $^{L A}$ & $108.6 \pm 1.85$ & $-11.7 \pm 0.64$ \\
\hline $6 \%$ SEON ${ }^{L A-B S A}$ & $61.7 \pm 1.15$ & $-12.9 \pm 0.55$ \\
\hline SEON ${ }^{L A-B S A} *$ MTO & $72.7 \pm 0.23$ & $-10.17 \pm 0.80$ \\
\hline
\end{tabular}

Notes: The zeta potentials decrease to similar values; the sizes differ significantly from each other. The broadness of the size distributions does not change greatly compared with measurements in water. All measurements were performed in triplicate. The values are presented as average \pm standard deviation.

Abbreviations: SEON ${ }^{\perp A}$, lauric acid-coated ferrofluid; SEON ${ }^{L A-B S A}$, bovine serum lauric acid/albumin hybrid-coated ferrofluid; SEON ${ }^{L A-B S A * A T O}$, bovine serum albumin/lauric acid-coated ferrofluid loaded with MTO; FCS, fetal calf serum; MTO, mitoxantrone. during the drying process prior to the TEM imaging, their size in the microscopy images is still quite consistent with the sizes obtained in the dynamic light scattering measurements of SEON ${ }^{\mathrm{LA}-\mathrm{BSA}}$. All the particles were located within a matrix of organic material. The edge of such a matrix can be seen in Figure 3C. The organic layer was too thick to allow good electron beam penetration in higher resolutions. However, the crystal lattices can be seen at a magnification of 325,000× (Figure 3D, see arrow).

\section{$\mathrm{pH}$-dependent zeta potential analysis of SEON ${ }^{L A-B S A}$ indicates a BSA surface}

To demonstrate colloidal stability over a wider $\mathrm{pH}$ range and to prove that BSA is located on the particle surface, we investigated the dependence of the zeta potential on the $\mathrm{pH}$ value. We set the $\mathrm{pH}$ by using $100 \mathrm{mM}$ ammonium formate buffer adjusted to different $\mathrm{pH}$-values (Figure 4). The point of zero charge of the particle surface was found to be around $\mathrm{pH}$ 5. Despite dilution in highly ionic buffer and the adsorption of ions to the particle surface, which is also reflected by the low absolute values of the zeta potential, the colloids were still stable after 24 hours. SEON ${ }^{\mathrm{LA}}$

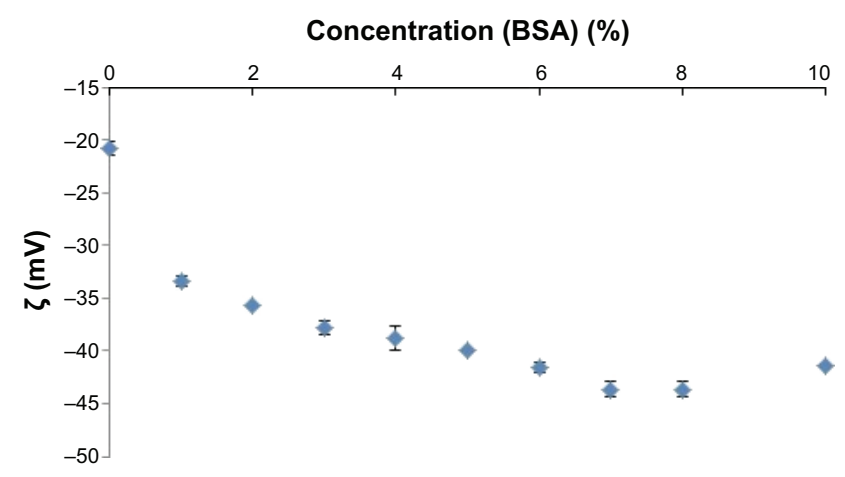

Figure 2 Decrease of the zeta potential with the amount of added BSA $(n=3)$. Abbreviation: BSA, bovine serum albumin. 

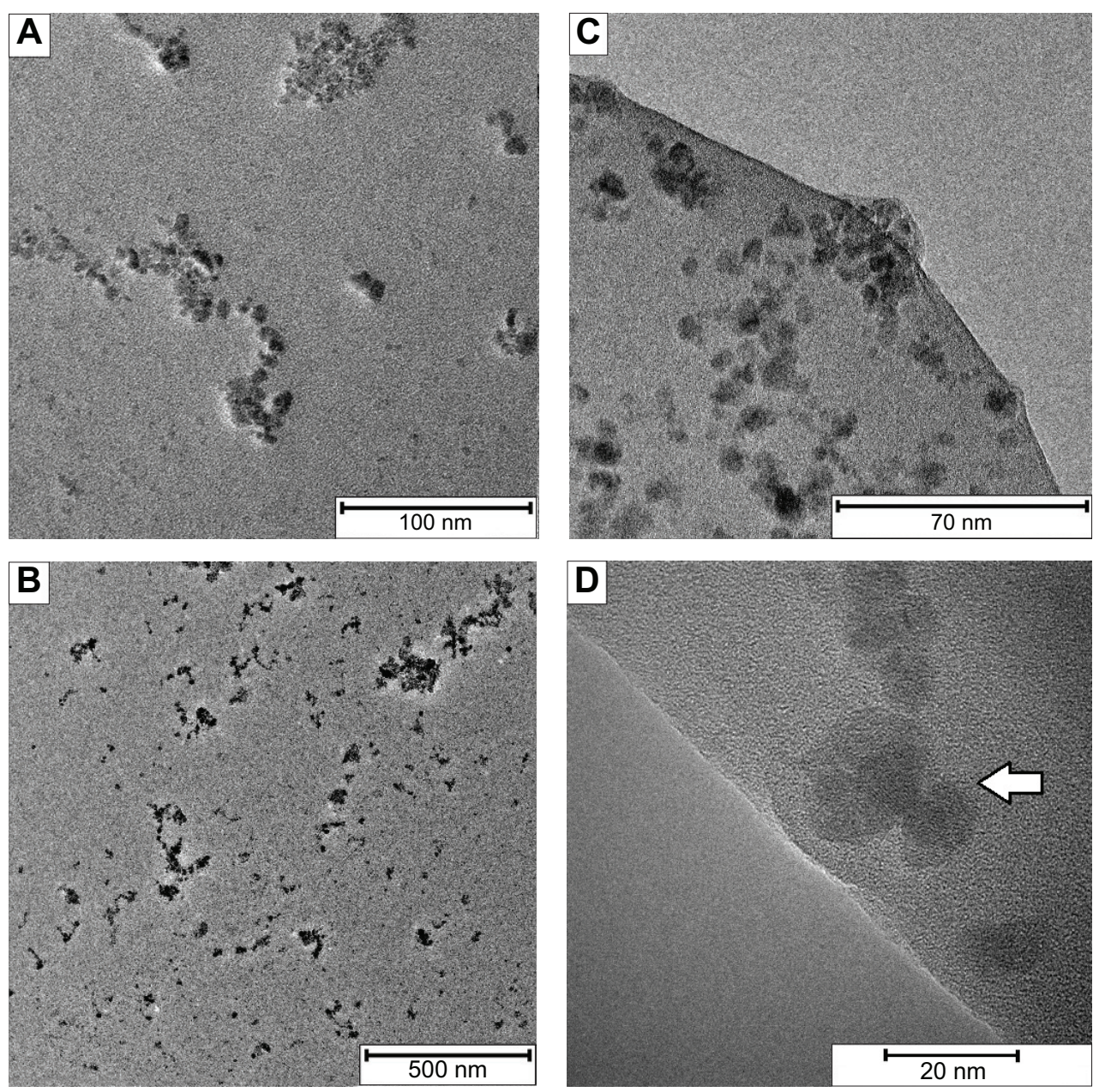

Figure 3 Transmission electron microscopy images of the 6\% SEON ${ }^{\text {LABBA }}$ sample.

Notes: (A) Core size distribution. (B) Low resolution image on which the aggregate size distributions can be observed. (C) Drying edge of the organic matrix with entrapped particles. (D) High resolution image. The arrow indicates the crystal lattice planes.

Abbreviation: SEON ${ }^{\text {LA-BSA }}$, bovine serum lauric acid/albumin hybrid-coated ferrofluid.

particles were not stable in these buffers and therefore could not be measured.

\section{FTIR measurements confirm the surfactant-protein core-shell structure}

After freeze-drying, the SEON ${ }^{\mathrm{LA}}$ had formed a sticky, black powder, whereas the SEON ${ }^{\mathrm{LA}-\mathrm{BSA}}$ samples had the

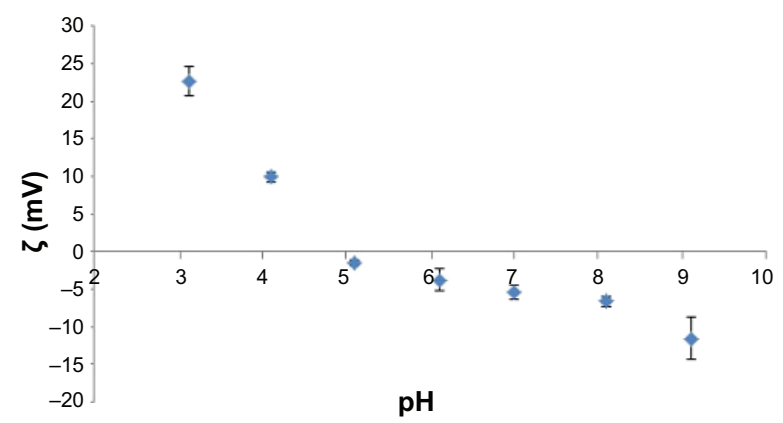

Figure 4 Dependence of the zeta potential $\zeta$ on the $\mathrm{pH}$ of the solution $(\mathrm{n}=3)$. typical fluffy structure of a dried polymer. With FTIR, we investigated the chemical structure of SEON ${ }^{L A}$ and SEON ${ }^{\mathrm{LA}-\mathrm{BSA}}$.

The $\mathrm{Fe}-\mathrm{O}$ peak at $588 \mathrm{~cm}^{-1}$ was clearly visible in the SEON ${ }^{\mathrm{LA}}$ and both SEON ${ }^{\mathrm{LA}-\mathrm{BSA}}$ samples. For the $6 \%$ SEON ${ }^{\mathrm{LA}-\mathrm{BSA}}$, we observed no major changes in comparison to the spectrum of pure BSA (Figure 5A). Lauric acid itself was apparently masked by the excess of BSA. However, upon multiple ultrafiltration of the $4 \%$ SEON ${ }^{\mathrm{LA}-\mathrm{BSA}}$, the lauric acid became visible. We observed a shift of the $\mathrm{C}-\mathrm{H}$ vibration peak from 2,932 to $2,924 \mathrm{~cm}^{-1}$ toward the $\mathrm{C}-\mathrm{H}$ vibrations of lauric acid. Also, the intensity ratio (absorbance/absorbance) of the two $\mathrm{C}-\mathrm{H}$ peaks changed as shown in Table 1 . An additional new peak at $2,848 \mathrm{~cm}^{-1}$ appears in the $4 \%$ SEON ${ }^{\mathrm{LA}-\mathrm{BSA}}$ sample. This peak is absent in pure BSA, but present in $\mathrm{SEON}^{\mathrm{LA}}$ (Figure 5B). This indicates the presence of remainders of lauric acid, which are apparently not removed by ultrafiltration. 

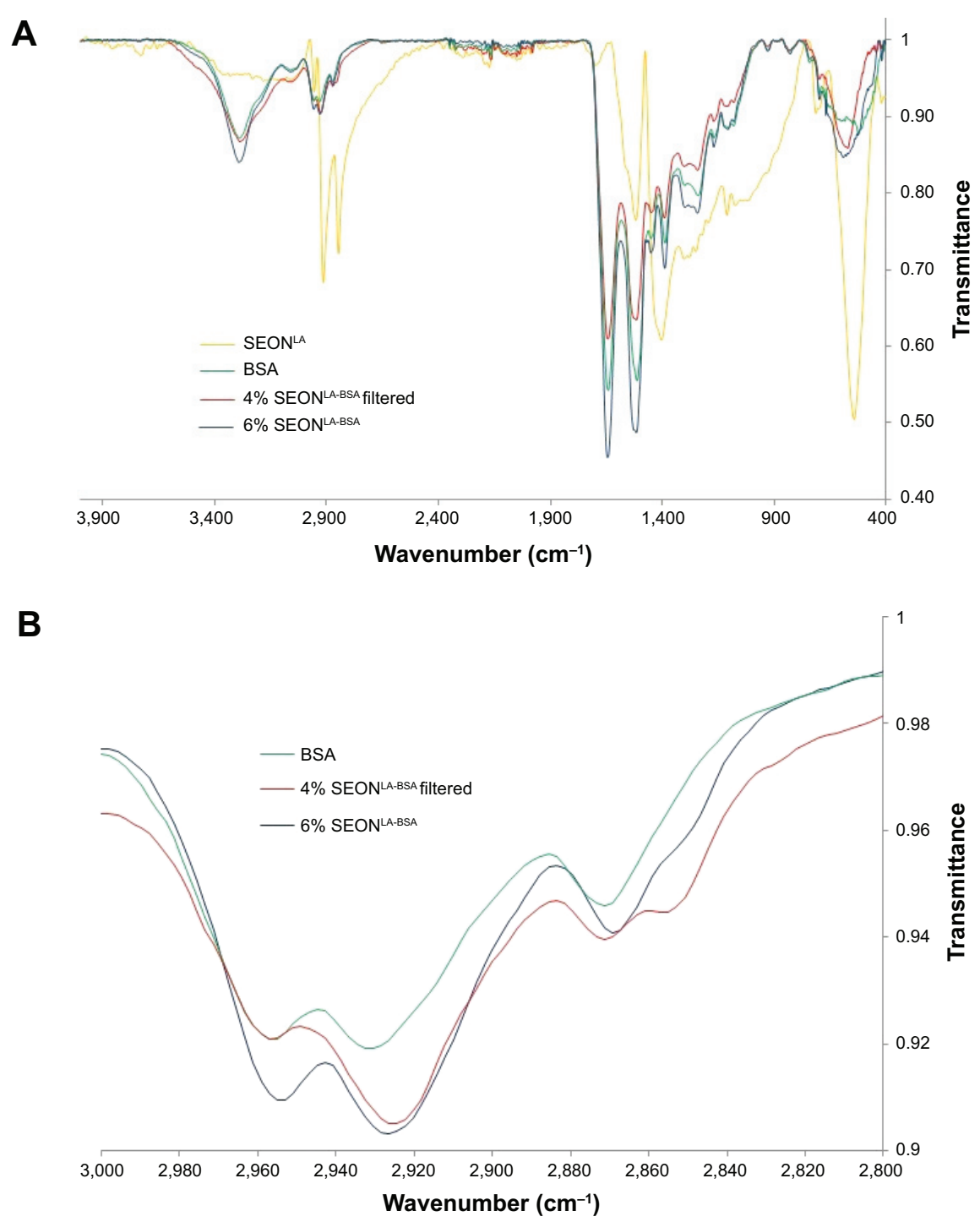

Figure 5 FTIR spectra of SEON ${ }^{L A}, 4 \%$ SEON ${ }^{L A-B S A}, 6 \%$ SEON ${ }^{L A-B S A}$, and pure BSA.

Notes: (A) Whole measurement range from 400 to $4,000 \mathrm{~cm}^{-1}$; (B) detailed view on the carbon-hydrogen vibration area, where the change of peaks can be seen. Note the new peak at $2,848 \mathrm{~cm}^{-1}$ and the change in the intensity ratios of the two peaks at 2,957 and $2,933-2,926 \mathrm{~cm}^{-1}$.

Abbreviations: FTIR, Fourier transform infrared spectroscopy; SEON ${ }^{L A}$, lauric acid-coated ferrofluid; SEON ${ }^{\text {LA-BSA, }}$, bovine serum lauric acid/albumin hybrid-coated ferrofluid; BSA, bovine serum albumin.

\section{Magnetic properties of SPIONs are still adequate after BSA coating}

The particles are still well attractable with a magnet. When injecting $20 \mu \mathrm{L}$ of SEON ${ }^{\mathrm{LA}-\mathrm{BSA}}$ into a cuvette filled with $2 \mathrm{~mL}$ of water, it is possible to attract the particles with a $0.55 \mathrm{~T}$ Neodymium magnet. Even after homogeneous dispersion of the particles in the solvent, it is possible to collect them by leaving the cuvette standing on top of the same magnet overnight. The so-prepared precipitate can, however, easily be redispersed to form a colloid again (Figure 6). This redispersion process is not possible after accumulation of SEON ${ }^{\mathrm{LA}}$. A drop of the solution in water is easily attractable with an electromagnet, and is released after turning off the current (Video S1).
The saturation magnetization data obtained with the SQUID-based susceptometer at high external field strengths of $\mathrm{M}(\mathrm{H}=5 \mathrm{~T})$ are an approximation of the saturation magnetization $\mathrm{M}_{\mathrm{s}}$. The magnetization curves are still slightly increasing at $5 \mathrm{~T}$, which means that the approximation is rather rough (Figure 7A). The values for the saturation magnetizations are given in Table 2. The magnetization curves measured with the VSM, normalized on the respective saturation magnetization of the samples, are depicted in Figure 7B. The samples show superparamagnetic behavior. The curves of all fluids are quite similar despite slight variation in the saturation magnetization. For the SQUID measurements, these variations lie within the limits of uncertainty. For VSM 

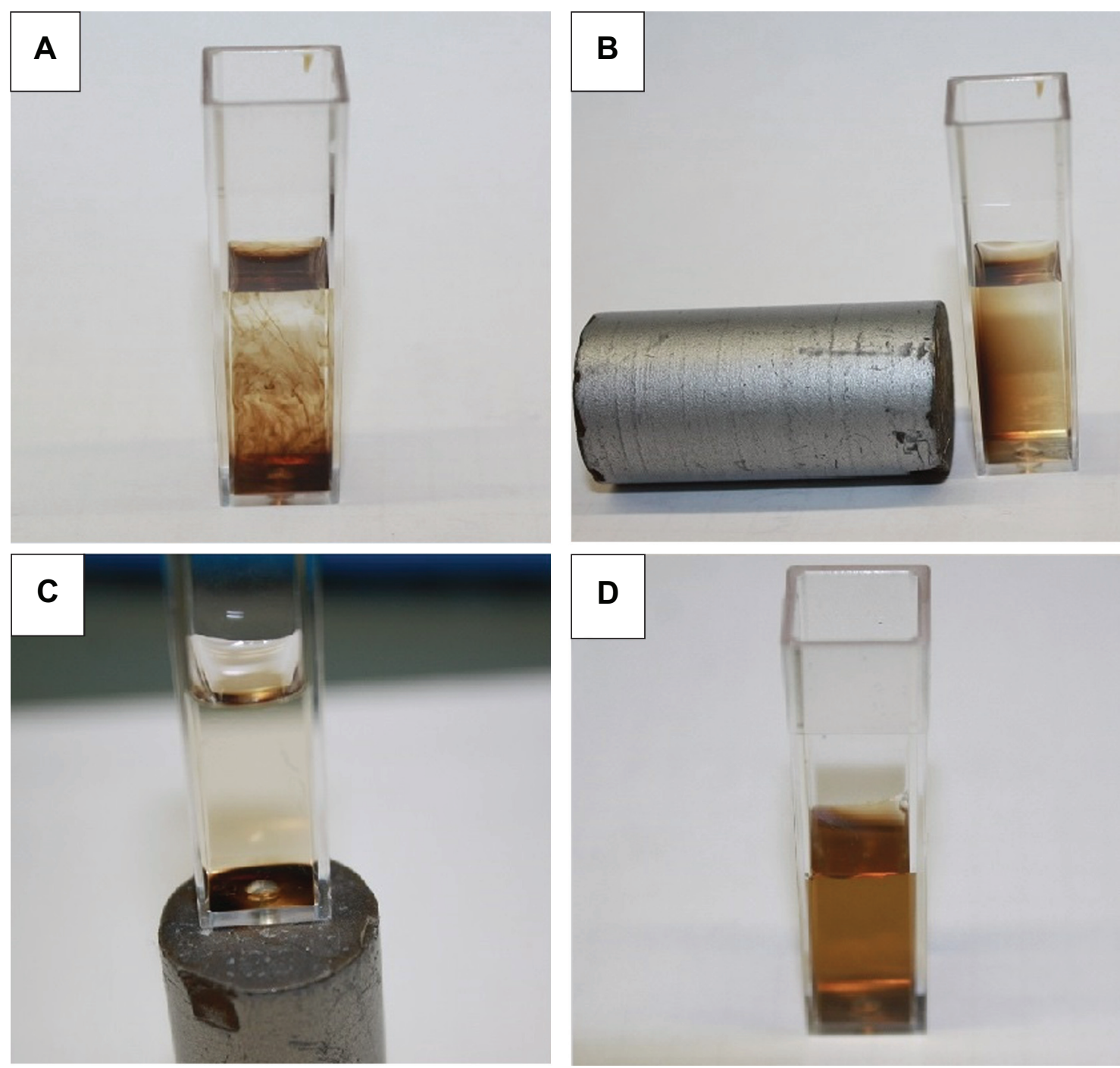

Figure 6 Manipulation of $20 \mu \mathrm{L}$ of SEON ${ }^{\text {LA-BSA }}$ particles in $2 \mathrm{~mL}$ of water with a magnet.

Notes: (A) Particles directly after addition without the magnet. (B) The same solution with a 0.55 T Neodymium magnet leads to a separation of SPIONs and water. (C) Complete attraction of the solution after homogenization and leaving it on top of the magnet overnight. (D) Rehomogenization of the solution from (C).

Abbreviations: SEON ${ }^{L A-B S A}$, bovine serum lauric acid/albumin hybrid-coated ferrofluid; SPION, superparamagnetic iron oxide nanoparticle.

A

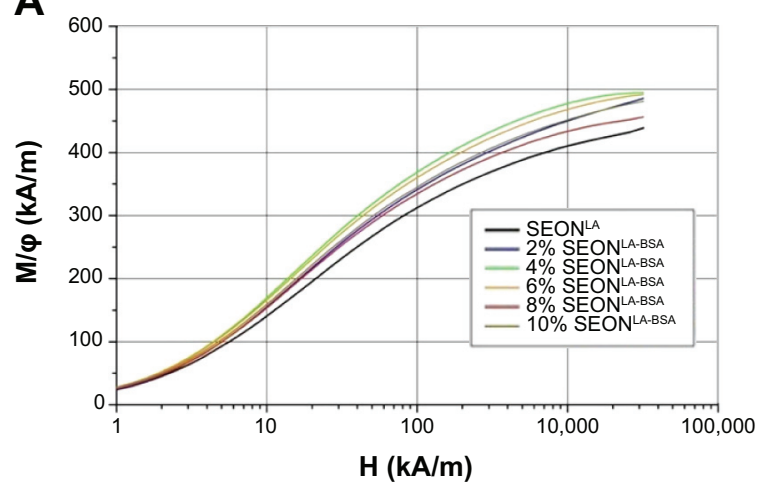

B

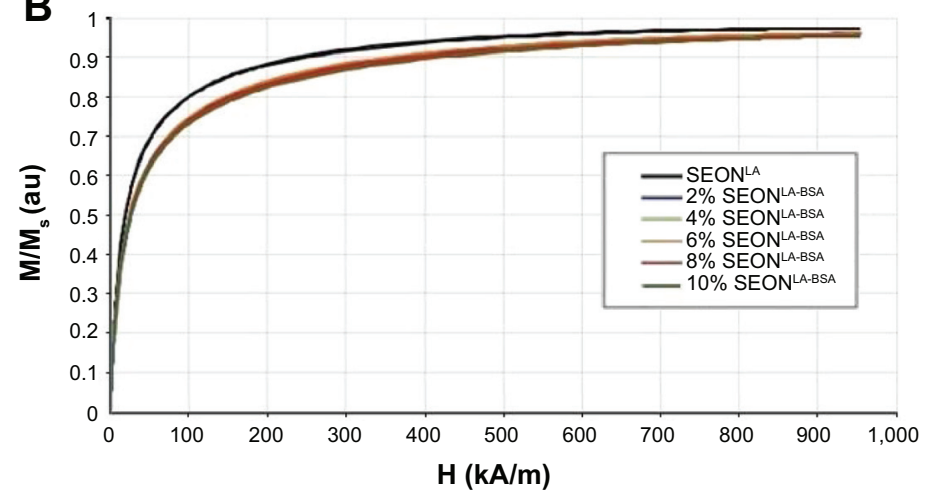

Figure 7 (A) Magnetization curves as measured by SQUID. (B) Normalized magnetization curves of the samples measured with the VSM.

Notes: The magnetization divided by the saturation magnetization of the respective sample is depicted for the respective magnetic field strength. Due to the high number of measured data points, the results are depicted as lines.

Abbreviations: $\mathrm{H}$, external magnetic field strength; $\mathrm{M}$, magnetization of the particles; Ms, saturation magnetization of the particles; SQUID, superconducting quantum interference device; VSM, vibrating sample magnetometry; SEON ${ }^{L A}$, lauric acid-coated ferrofluid; SEON ${ }^{L A-B S A}$, bovine serum lauric acid/albumin hybrid-coated ferrofluid. 
Table 2 FTIR intensity ratios (Abs I/Abs2) and wavenumber shifts of the two $\mathrm{C}-\mathrm{H}$ swinging peaks at around 2,957 and $2,923 \mathrm{~cm}^{-1}$

\begin{tabular}{lllll}
\hline & BSA & 6\% SEON & 4A-BSA & 4\% SEON \\
\hline Intensity ratio & 0.98 & 0.94 & 0.83 & SEON \\
Peak I $\left(\mathrm{cm}^{-1}\right)$ & 2,957 & 2,957 & 2,957 & 0.53 \\
Peak 2 $\left(\mathrm{cm}^{-1}\right)$ & 2,933 & 2,928 & 2,926 & 2,955 \\
\hline
\end{tabular}

Notes: Both the intensity ratio and the wavenumber of peak 2 (the peak with the highest intensity in the spectrum of SEON ${ }^{\perp A}$ ) shift toward SEON ${ }^{L A}$ by reduction of the protein payload.

Abbreviations: FTIR, Fourier transform infrared spectroscopy; Abs I, absorbance peak 1; Abs2, absorbance peak 2; BSA, bovine serum albumin; SEON ${ }^{\perp A}$, lauric acidcoated ferrofluid; SEON ${ }^{\text {AABSA }}$, bovine serum lauric acid/albumin hybrid-coated

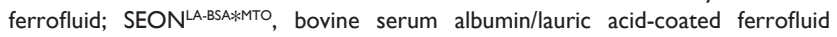
loaded with MTO; MTO, mitoxantrone.

measurements, they correlate with increases in $\Phi$, and thus might be attributed to variation in the iron concentration measurements. After normalization to $\Phi$, however, the results are in good concordance with the results obtained by SQUID. Hence, $\mathrm{M}(\mathrm{H})$ data proved that the addition of BSA has no considerable influence on the actual magnetic behavior of the magnetic nanoparticles.

\section{BSA-coated particles are stable in ethylenediaminetetraacetic acid-whole blood}

Five minutes after dilution in blood, aggregates were already visible on the SEON ${ }^{\mathrm{LA}}$ sample. Over the course of an hour, massive accumulation of the particles occurred here. In contrast, the SEON ${ }^{\mathrm{LA}-\mathrm{BSA}}$ was stable over the whole observing period. Neither macro- nor microscopically were any aggregates visible in this sample (Figure 8A).

Under the light microscope, we observed particle aggregates that sometimes included or occluded erythrocytes with the lauric acid-stabilized sample. The erythrocytes in the vicinity of these aggregates show altered morphology, they appear deformed as compared with the spherical shape of healthy erythrocytes. In the SEON ${ }^{\mathrm{LA}-\mathrm{BSA}}$ sample, we did not observe any major visible effects as compared with control (Figure 8B). As the detection limit of our microscopy system lies between 200 and $300 \mathrm{~nm}$, we concluded that no major
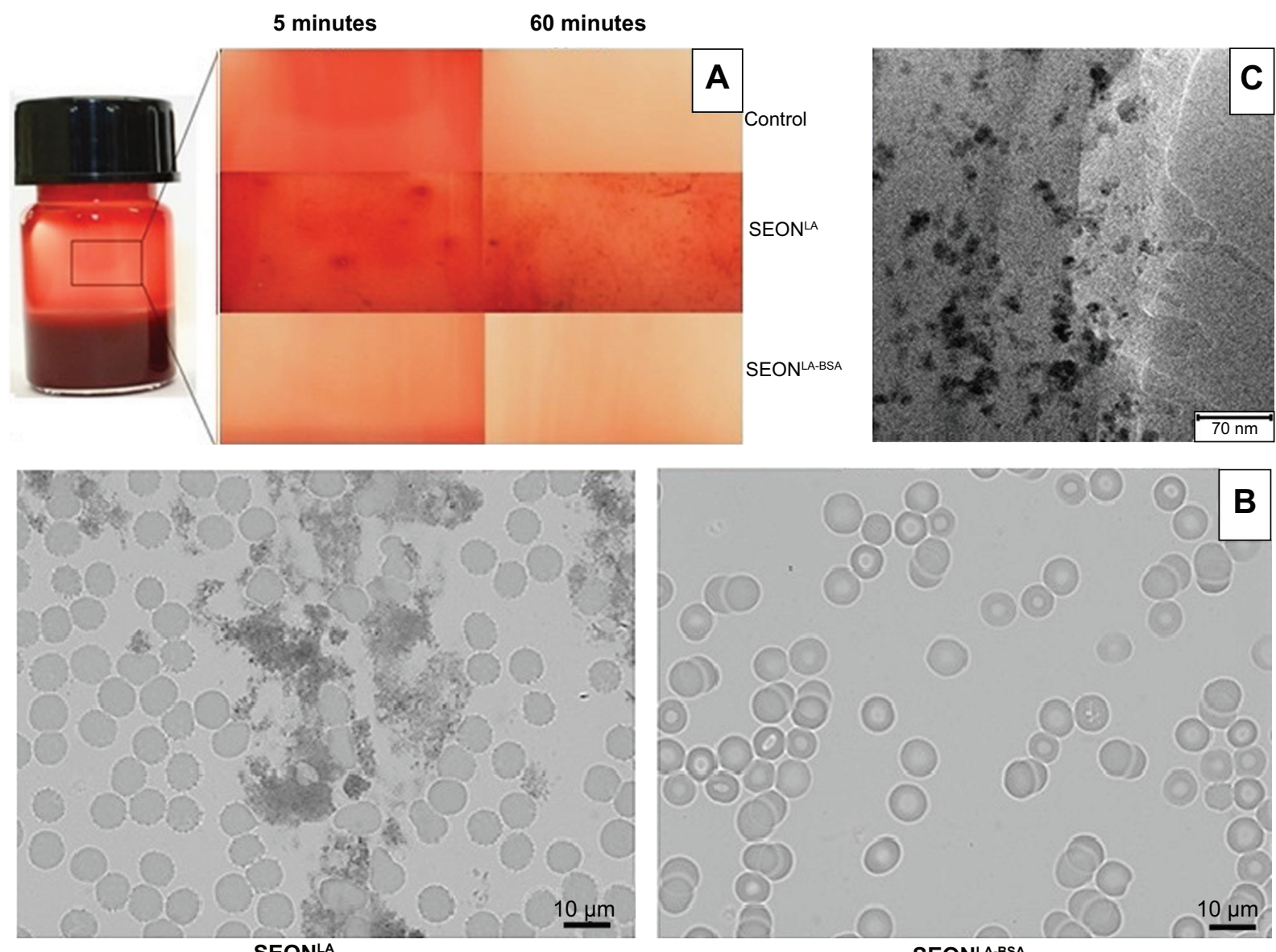

SEONLA

SEONLA-BSA

Figure 8 Investigations on the stability of SEON ${ }^{L A}$ and SEON ${ }^{L A-B S A}$ in human whole blood (A) ethylenediaminetetraacetic acid-stabilized whole blood with or without particles after 5 and 60 minutes. The pictures were taken after gentle shaking of the sample. (B) Microscopic images (magnification I,I00-fold) of SEON ${ }^{L A}$ and SEON ${ }^{L A-B S A}$ in blood after 30 minutes of incubation. (C) TEM image of particle clusters of SEONLA-BSA after separation of the cellular blood compounds.

Note: The particle clusters are still visible with an aggregate diameter and shape similar to the measurements in pure water.

Abbreviations: SEON ${ }^{L A}$, lauric acid-coated ferrofluid; SEON ${ }^{L A-B S A}$, bovine serum lauric acid/albumin hybrid-coated ferrofluid; TEM, transmission electron microscopy. 
aggregates above that size had formed and proceeded with centrifugation.

The TEM images of this serum supernatant showed thick layers of organic material. However, at the thinner edges of these layers, particles can be seen again. We observed no visible changes in size or shape of the clusters and single cores here (Figure 8C).

\section{BSA coating reduces the toxicity of the nanoparticles}

The total cell count, as measured with a MUSE cell analyzer after 24 and 48 hours of incubation with SEON ${ }^{\mathrm{LA}}$ or SEON ${ }^{\mathrm{LA}-\mathrm{BSA}}$, is depicted in Figure 9A. From 24 to 48 hours, the cell count of the untreated control cells increases from $5 \times 10^{5}$ to $12 \times 10^{5}$ due to cellular proliferation. Treatment of cells with SEON ${ }^{\mathrm{LA}}$ and SEON ${ }^{\mathrm{LA}-\mathrm{BSA}}$ clearly decreases the amount of viable cells in a dose-dependent manner. Remarkably, the critical concentration for a significant reduction of the viable cell count after 48 hours is $50 \mu \mathrm{g} / \mathrm{mL}$ for $\mathrm{SEON}^{\mathrm{LA}}$ and $75 \mu \mathrm{g} / \mathrm{mL}$ for SEON ${ }^{\mathrm{LA}-\mathrm{BSA}}(P<0.05)$, respectively. SSC analysis can be used to assess the increase in granularity of the cells reflecting nanoparticle uptake in flow cytometry. ${ }^{24}$ As dying cells show an altered morphology due to blebbing processes in apoptosis or membrane rupture in necrosis, only viable cells must be analyzed for SSC determination. We therefore evaluated the SSC of cells with intact mitochondrial membrane potential (DiI-positive cells), showing a significant concentration-dependent increase in the SSC of Jurkat cells after incubation with SEON ${ }^{\mathrm{LA}}$ and SEON ${ }^{\mathrm{LA}-\mathrm{BSA}}$ after 24 and 48 hours (Figure 9B). After 24 hours, SEON ${ }^{\text {LA }}$ treated cells showed an increased SSC reflecting an enhanced nanoparticle uptake compared with the SEON ${ }^{\mathrm{LA}-\mathrm{BSA}}$-treated cells. Interestingly, the SSC did not further increase during prolonged incubation with SEON ${ }^{\mathrm{LA}}$, whereas cells incubated with SEON ${ }^{\mathrm{LA}-\mathrm{BSA}}$ indeed continued taking up nanoparticles during the observation period of 48 hours. Thus, one might speculate that the protein shell decelerates incorporation of particles into the cells.

The cells incubated with $150 \mu \mathrm{g} / \mathrm{mL}$ and $200 \mu \mathrm{g} / \mathrm{mL}$ SEON ${ }^{\mathrm{LA}}$ could not be analyzed due to low cell count (below 300 cells per well).

We employed PIT staining after 48 hours to determine the effect of the nanoparticles on cell cycle and DNA degradation (Figure 9C). Cells treated with SEON ${ }^{\mathrm{LA}}$ exhibited a dosedependent decomposition of DNA as reflected by the appearance of subG1-DNA; thus, $96.8 \% \pm 1.26 \%$ of cells treated with $200 \mu \mathrm{g} / \mathrm{mL}$ showed DNA degradation. With SEON ${ }^{\text {LA-BSA }}$, this effect occurred only moderately at the highest concentrations; in comparison, only $19.33 \% \pm 0.44 \%$ of the cells treated with $200 \mu \mathrm{g} / \mathrm{mL}$ SEON ${ }^{\text {LA-BSA }}$ harbored sub-G1 DNA.

With AxA5 staining, we analyzed the exposure of phosphatidylserine on the outer side of the plasma membrane as an indicator for apoptosis. Counterstaining with the plasma membrane-impermeable dye PI was performed to detect plasma membrane rupture as an indicator of necrosis (Figure 9D). Thereby, we can separate healthy (AxA5 and PI negative) from apoptotic (AxA5 positive, but PI negative) and necrotic (AxA5 and PI positive) cells. We observed a significant, concentration-dependent decrease in the amount of viable cells after 24 and 48 hours for $\mathrm{SEON}^{\mathrm{LA}}$. At the highest concentration of SEON ${ }^{\mathrm{LA}}$ tested, after 48 hours hardly any viable cells could be detected. Remarkably, SEON ${ }^{\text {LA-BSA }}$ particles did not cause a decrease in viable cells below $76.6 \% \pm 0.012 \%$ even after 48 hours of incubation at the highest concentrations used. Note that the appearance of $\mathrm{Ax}+\mathrm{PI}-$ cells after 48 hours in SEON ${ }^{\mathrm{LA}}$ treatment means loss of PI fluorescence and indicates DNA degradation during late phases of cell death ("secondary necrosis"). This effect can also be seen in the PIT staining in Figure 9C. Using the fluorescent dye DiI, we analyzed the mitochondrial membrane potential, an indicator for viable unstressed cells. The drop in DiI fluorescence, in contrast, is an early marker for cell death (Figure 9E). In agreement with the results of the AxA5/PI staining and the cell count measurements, the cells were barely affected by nanoparticle concentrations $<50 \mu \mathrm{g} / \mathrm{mL}$. At total iron concentrations of $50 \mu \mathrm{g} / \mathrm{mL}$ and above, however, the overall DiI-positive count of the Jurkat cells treated with SEON ${ }^{\mathrm{LA}}$ strongly decreased in a significant, dose-dependent manner. The number of viable cells treated with SEON ${ }^{\mathrm{LA}-\mathrm{BSA}}$ was only moderately affected as compared with control. Altogether, SEON ${ }^{\mathrm{LA}}$ strongly induces cell death at concentrations of $100 \mu \mathrm{g} / \mathrm{mL}$ and above, whereas the corresponding SEON ${ }^{\mathrm{LA}-\mathrm{BSA}}$ did not induce excessive cell death. Reduction in the amount of viable cells after treatment with SEON ${ }^{\mathrm{LA}-\mathrm{BSA}}$, therefore, is mainly the result of reduced cell proliferation.

\section{Growth of HUVECs depends on the amount of added SEON ${ }^{L A-B S A}$}

The toxicity of SEON ${ }^{\mathrm{LA}-\mathrm{BSA}}$ on HUVECs was analyzed with the help of impedance measurements using the xCELLigence system. The system calculates the so-called "cell-index" from the impedance measured across the bottom of the wells, which depends on the numbers of adherent cells and the strength of adherence. The results in Figure 10 show that all samples had the same cell-index 24 hours after seeding 
A

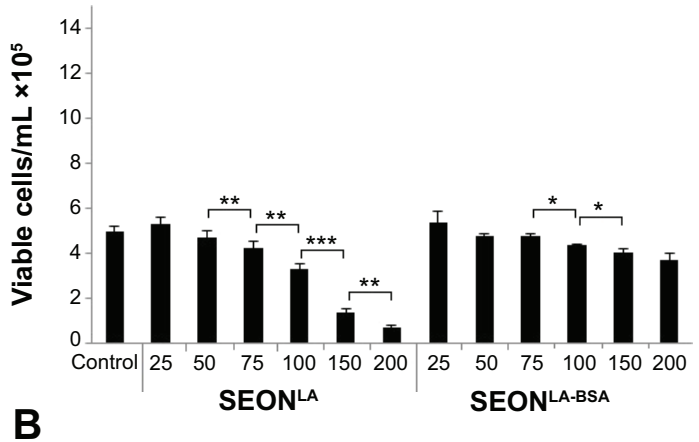

B

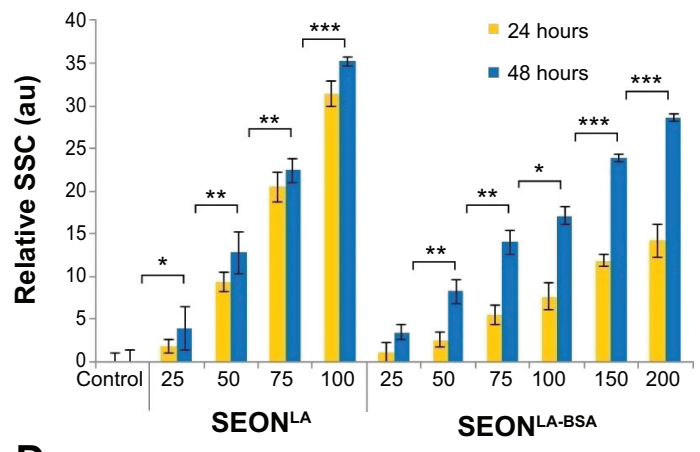

D
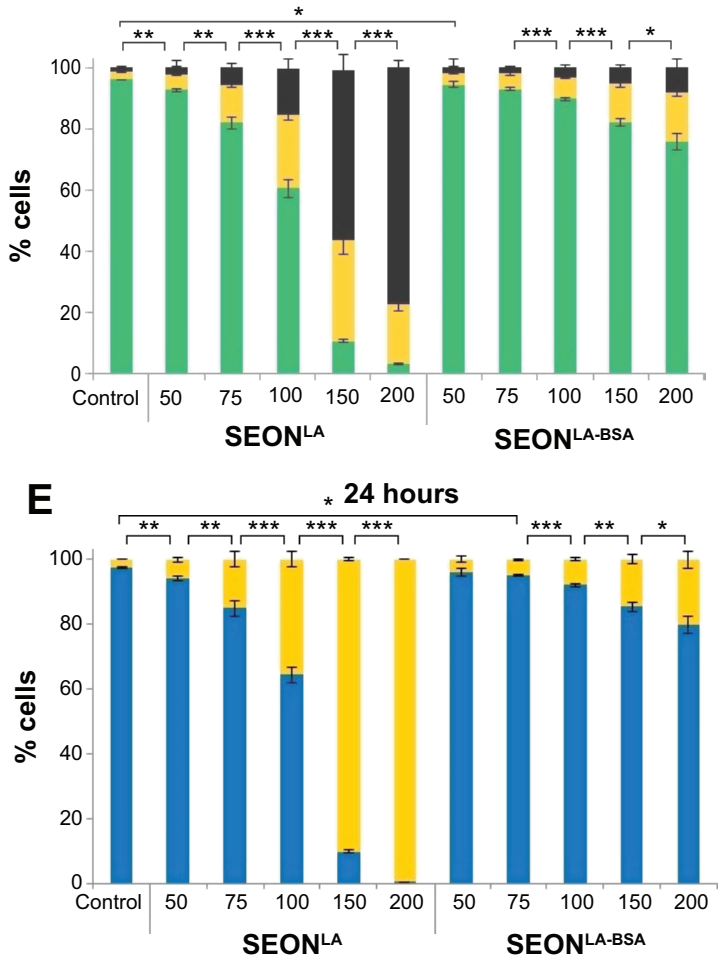

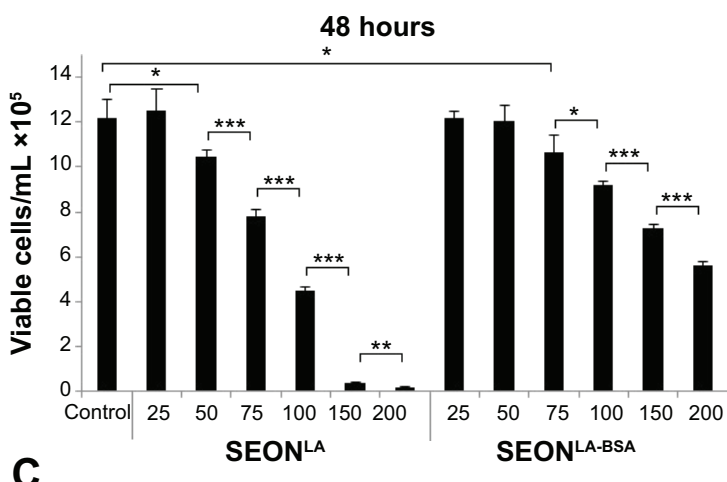

C
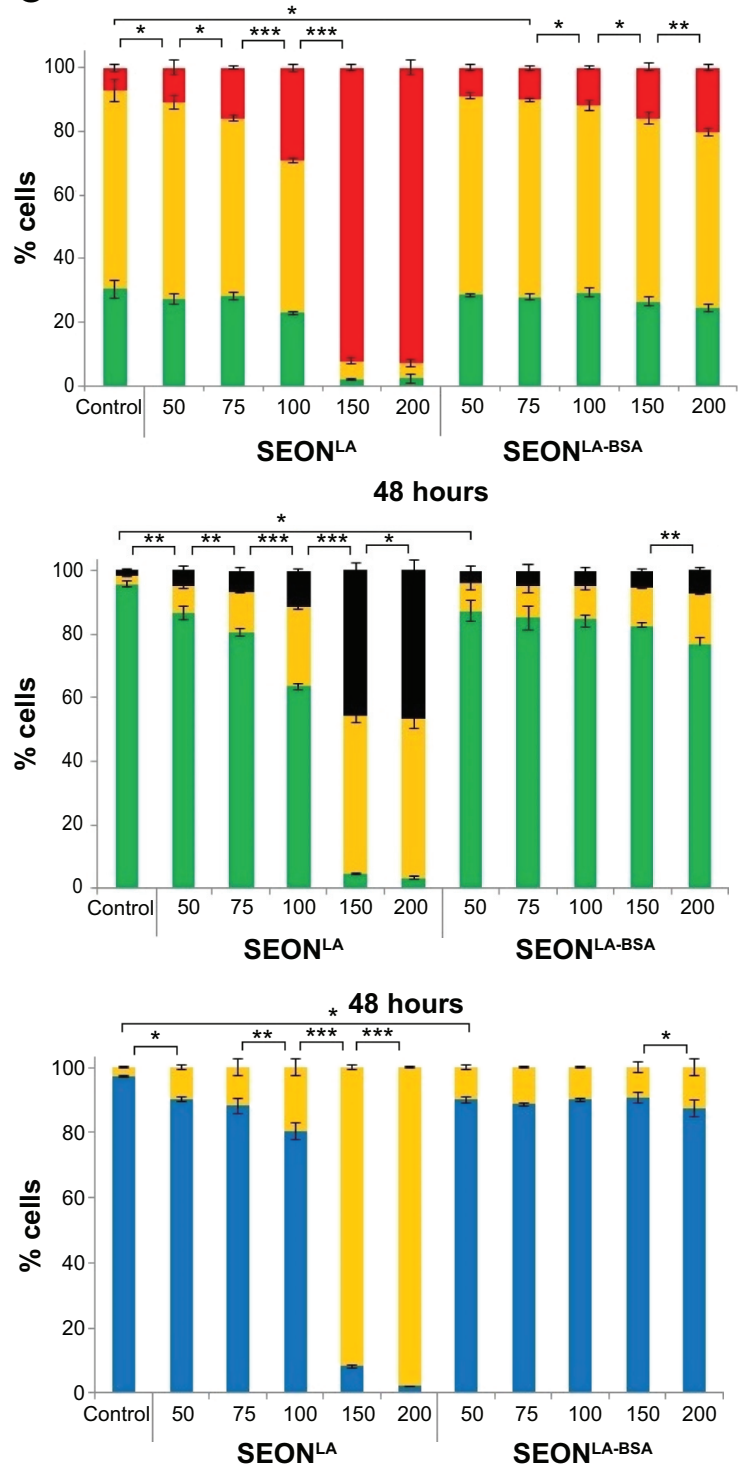

Figure 9 Comparison of the effects of SEON ${ }^{L A}$ or SEON ${ }^{L A-B S A}$ on viability of Jurkat cells.

Notes: (A) Cell count of Jurkat cells after incubation with SEON ${ }^{L A}$ or SEON ${ }^{L A-B S A}$ as determined by a MUSE cell analyzer after 24 and 48 hours. (B) SSC analysis of Jurkat cells after 24 hours (yellow bars) and 48 hours (blue bars) of incubation with different concentrations of SEON ${ }^{L A}$ or SEON ${ }^{L A-B S A}$. (C) Results of the PI-Triton X-I00 staining. Green bars indicate cells with a normal amount of DNA (GI), yellow bars indicate cells with doubled DNA amount (G2), and red bars indicate cells with fragmented DNA (subGI). (D) AxA5 - PI staining of Jurkat cells treated with different amounts of SEON ${ }^{L A}$ and SEON LA-BSA for 24 and 48 hours. Green bars indicate viable (both parameters negative) cells, yellow bars indicate apoptotic (AxA5-positive, but PI-negative) cells and black bars indicate necrotic (both parameters positive) cells. (E) Dil-positive count of cells treated with the respective ferrofluid for 24 and 48 hours. Blue bars indicate viable cells (Dil-positive), yellow bars indicate cells with reduced mitochondrial activity. All concentrations are given in $\mu \mathrm{g} / \mathrm{mL}$; all measurements were performed in quadruplicate. The asterisks indicate the $P$-value obtained from Student's $t$-tests for statistical significance. $* P<0.05 ; * * P<0.005 ; * * * P<0.0005$.

Abbreviations: SEON ${ }^{L A}$, lauric acid-coated ferrofluid; SEON ${ }^{L A-B S A}$, bovine serum lauric acid/albumin hybrid-coated ferrofluid; TEM, transmission electron microscopy; AxA5, Annexin V; Dil, hexamethylindodicarbocyanine iodide dye; PI, propidium iodide; SSC, side scatter. 


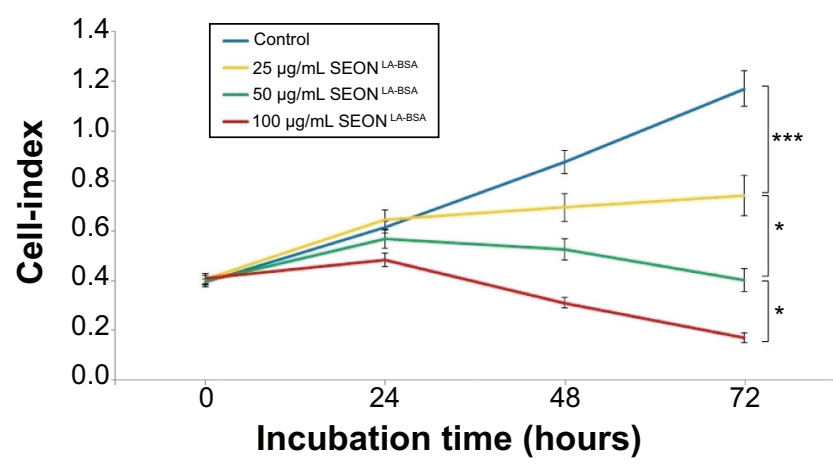

Figure 10 Real-time analysis of the effect of SEON ${ }^{\text {LA-BSA }}$ treatment on endothelial cell growth and viability.

Notes: HUVECs were seeded in 16-well E-plates at a concentration of $1 \times 10^{3} /$ well and monitored for 24 hours. Subsequently, the nanoparticles were added to the wells at end concentrations of $0 \mu \mathrm{g} / \mathrm{mL}, 25 \mu \mathrm{g} / \mathrm{mL}, 50 \mu \mathrm{g} / \mathrm{mL}$, and $100 \mu \mathrm{g} / \mathrm{mL}$ SEON LA-BSA Cell growth was monitored over 4 days. The graph shows the development of the cell index over time for all four samples.

Abbreviations: SEON ${ }^{L A-B S A}$, bovine serum lauric acid/albumin hybrid-coated ferrofluid; HUVEC, Human umbilical vein endothelial cell.

(before nanoparticle addition, $\mathrm{t}=0$ ), indicative of the same initial conditions. After 24 hours of nanoparticle treatment, first differences in cell-indices were detectable, with a small but observable decrease of the cell-index at $100 \mu \mathrm{g} / \mathrm{mL}$. Nanoparticle treatments for 48 and 72 hours resulted in a decreased cell-index for all nanoparticle-containing samples compared with untreated controls. In HUVECs treated with $25 \mu \mathrm{g} / \mathrm{mL}$ of nanoparticles, a decreased cell-index as compared with control was observed at 48 and 72 hours. However, during the whole experiment, the cell-index of HUVECs treated with $25 \mu \mathrm{g} / \mathrm{mL} \mathrm{SEON}^{\mathrm{LA}-\mathrm{BSA}}$ showed a slow increase. In HUVECs treated with $50 \mu \mathrm{g} / \mathrm{mL} \mathrm{SEON}^{\mathrm{LA}-\mathrm{BSA}}$, a cell-index comparable to control was observed after 24 hours, but after 48 hours the index decreased in comparison to 24 hours and continued to decrease down to an initial pre-treatment value at 72 hours indicating a growth arrest. Similar tendencies were observed for HUVECs treated with $100 \mu \mathrm{g} / \mathrm{mL}$ SEON ${ }^{\mathrm{LA}-\mathrm{BSA}}$, whereby the cell-index was dramatically decreased already after 48 hours indicative of progressing cell death and detachment. Control measurements revealed that the particles alone did not significantly change the impedance as compared with controls at concentrations of $1 \mu \mathrm{g} / \mathrm{mL}, 10 \mu \mathrm{g} / \mathrm{mL}$, and $100 \mu \mathrm{g} / \mathrm{mL}$ iron (Figure S2).

\section{MTO is slowly released from SEONLA-BSA*MTO}

Upon incubation in $\mathrm{PBS}$ at $37^{\circ} \mathrm{C}$, MTO was very slowly released from the system over 72 hours as depicted in Figure 11. Surprisingly, we did not observe any burst release, indicating that the binding of the drug to the particles is not just electrostatic interaction. During the observed time period, only

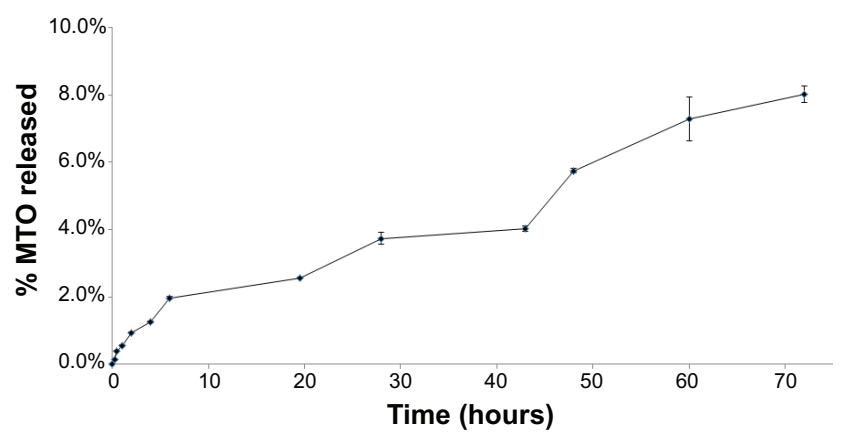

Figure I I Release kinetics of MTO from SEON 2 A-BSA*MTO in PBS at $37^{\circ} \mathrm{C}$.

Notes: No burst release was observed; MTO is slowly released with linear kinetics. After 72 hours, only $8.01 \% \pm 0.24 \%$ of the original amount of MTO is located outside the membrane. In the lysate of particle suspension after 72 hours, we detected $93.38 \% \pm 2.72 \%$ of the original amount of MTO. All measurements were performed in triplicate.

Abbreviations: MTO, mitoxantrone; SEON ${ }^{L A-B S A^{*} M T O}$, bovine serum albumin/lauric acid-coated ferrofluid loaded with MTO; PBS, phosphate-buffered saline.

$8.01 \% \pm 0.18 \%$ of the drug were released with a linear release kinetics. After 72 hours, $93.4 \% \pm 2.7 \%$ of the original amount of MTO were still detected in the particle lysate.

\section{SEON ${ }^{L A-B S A * M T O}$ possess great therapeutic potential in vitro}

For SEON ${ }^{\mathrm{LA}-\mathrm{BSA}}$ loaded with MTO, we observed a clear, concentration- and time-dependent cytotoxic effect on Jurkat cells (Figure 12). Upon addition of free MTO or SEON ${ }^{\mathrm{LA}-\mathrm{BSA} * \mathrm{MTO}}$, the cells first became apoptotic, and then, after 48 hours, necrotic as demonstrated by AxA5/ PI and DiI staining (Figure 12A and B). The cytotoxicity was clearly dependent on the MTO concentration. Note that after 48 hours, the relative number of viable cells was decreased by $42 \%$ for $0.025 \mu \mathrm{g} / \mathrm{mL} \mathrm{SEON}^{\mathrm{LA}-\mathrm{BSA} * \mathrm{MTO}}$ as compared with the cells treated with $0.025 \mu \mathrm{g} / \mathrm{mL}$ of free MTO. For $0.05 \mu \mathrm{g} / \mathrm{mL} \mathrm{SEON}^{\mathrm{LA}-\mathrm{BSA} * \text { MTO }}$, the number is decreased by $45 \%$ and for $0.1 \mu \mathrm{g} / \mathrm{mL}$ the number of viable cells is $15 \%$ lower. The effect is statistically significant for the $0.025 \mu \mathrm{g} / \mathrm{mL}$ and $0.05 \mu \mathrm{g} / \mathrm{mL}$ samples $(P<0.05)$. This indicates an increase in cell death when the drug is attached to the particles. The amount of MTO inside viable cells increases in a dose-dependent way. However, the MTO content of the cells is not significantly enhanced by its coupling to the particles (Figure S3). The mitochondrial membrane potential decreased in agreement to these results, as depicted in Figure 12B. Finally, we also saw an interesting effect of MTO and SEON ${ }^{\mathrm{LA}-\mathrm{BSA} * \text { MTO }}$ on the cell cycle (Figure 12C). Small concentrations of the drug increase the amount of cells with doubled DNA, whereas higher amounts led to high DNA fragmentation. Due to serious DNA damage caused by the 

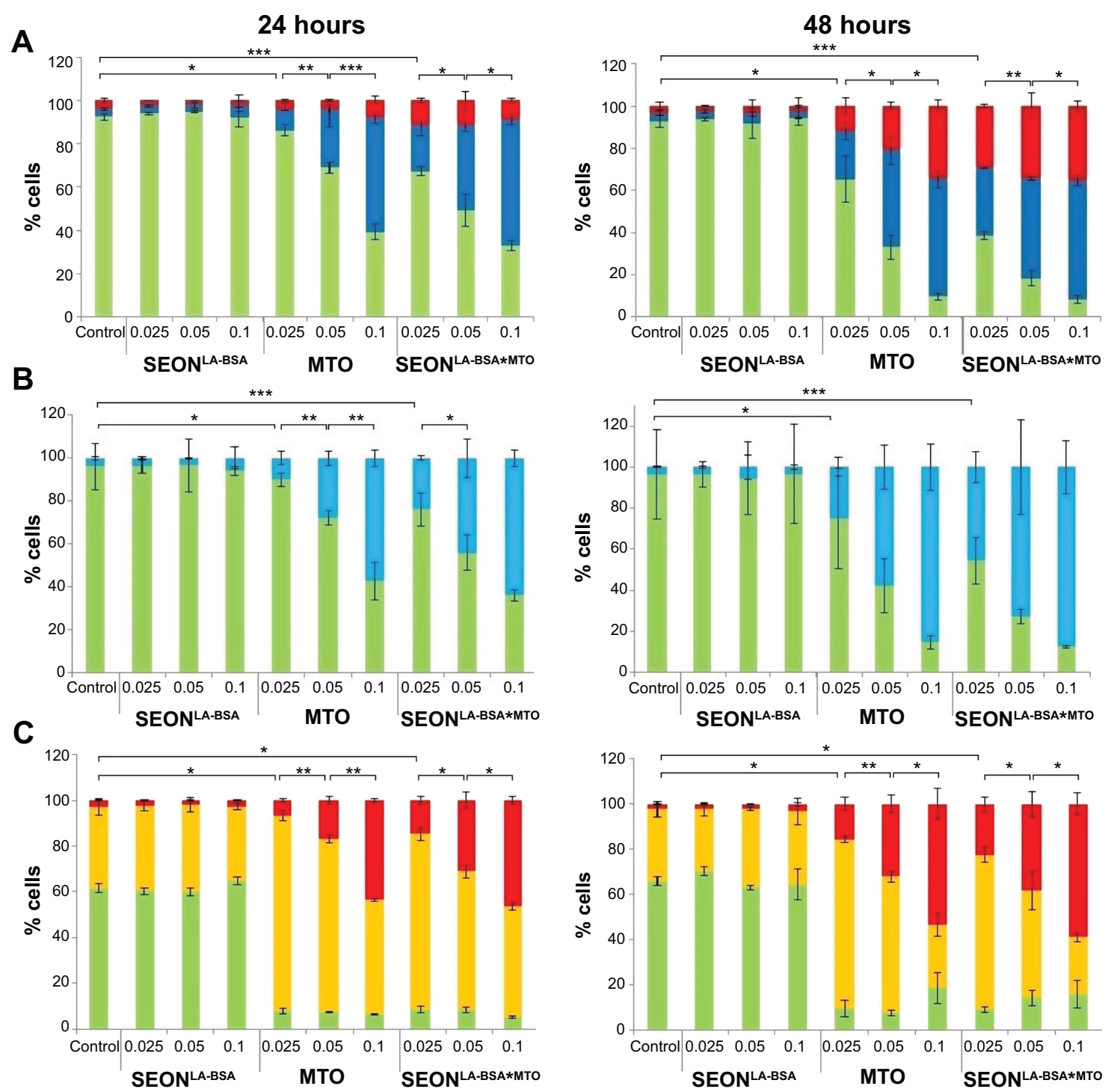

Figure 12 Comparison of the effects of SEON ${ }^{\text {LA-BSA }}$, pure MTO, and SEON LA-BSA*MTO on Jurkat cells after 24 hours (left) and 48 hours (right) by flow cytometry. Notes: All the concentrations are given in $\mu \mathrm{g} / \mathrm{mL}$ MTO. For SEON ${ }^{\mathrm{LA}-B S A}$, the total iron concentrations of SEON ${ }^{L A-B S A * M T O}$ were used. (A) AxA5-PI staining of Jurkat cells treated with different amounts of the respective ferrofluids. Green bars indicate viable (both parameters negative) cells, blue bars indicate apoptotic (AxA5-positive, but PI-negative) cells and red bars indicate necrotic (both parameters positive) cells. Significance analysis was performed on viable cells. (B) Dil staining of the same cells. Green bars indicate Dil-positive cells and blue bars indicate Dil-negative cells. Significance analysis was performed on Dil-positive cells. (C) Results of the PIT X-I00 staining. Green bars indicate cells with a normal amount of DNA (GI), yellow bars indicate cells with doubled DNA amount (G2), and red bars indicate cells with fragmented DNA (subGI). Significance analysis was performed on sub-GI cells. The asterisks indicate the $P$-value obtained from Student's $t$-tests for statistical significance. $* P<0.05$; $* * P<0.005 ; * * * P<0.0005$.

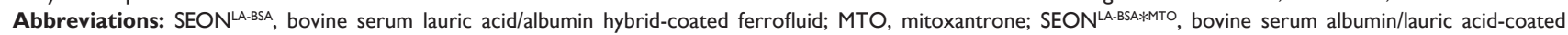
ferrofluid loaded with MTO; AxA5, Annexin V; Dil, hexamethylindodicarbocyanine iodide dye; PIT X-100, propidium iodide - Triton X-I00.

Table 3 Saturation magnetizations $M_{s}$ of the different ferrofluid samples as measured by SQUID and VSM

\begin{tabular}{|c|c|c|c|c|c|}
\hline & $\Phi$ (vol\%) & $M_{s} / \Phi(\mathrm{kA} / \mathrm{m})$ & $\Phi$ (vol\%) & $M_{s}(\mathrm{~A} / \mathrm{m})$ & $M_{s} / \Phi(\mathrm{kA} / \mathrm{m})$ \\
\hline SEONLA & 0.0081 & $432 \pm 30$ & 0.041 & $185 \pm 2$ & $45 I \pm 49$ \\
\hline $2 \%$ SEON $N^{L A-B S A}$ & 0.011 & $480 \pm 30$ & 0.044 & $200 \pm 2$ & $455 \pm 46$ \\
\hline $4 \%$ SEON $N^{L A-B S A}$ & 0.0074 & $494 \pm 30$ & 0.044 & $199 \pm 2$ & $452 \pm 46$ \\
\hline $6 \%$ SEON ${ }^{L A-B S A}$ & 0.0074 & $490 \pm 30$ & 0.044 & $200 \pm 2$ & $455 \pm 46$ \\
\hline $8 \%$ SEON $N^{L A-B S A}$ & 0.0077 & $452 \pm 30$ & 0.048 & $215 \pm 2$ & $448 \pm 63$ \\
\hline \multirow[t]{2}{*}{$10 \%$ SEON } & 0.024 & $485 \pm 30$ & 0.055 & $247 \pm 2$ & $449 \pm 55$ \\
\hline & SQUID & & & VSM & \\
\hline
\end{tabular}

Notes: The SQUID values are normalized on the volume fraction of magnetic material $\Phi$. With VSM, the samples were measured without further dilution. When normalized on $\Phi$ the results are in concordance with the results obtained by SQUID. The values are presented as average \pm standard deviation.

Abbreviations: SQUID, superconducting quantum interference device; VSM, vibrating sample magnetometry; SEON ${ }^{L A}$, lauric acid-coated ferrofluid; SEON ${ }^{L A-B S A}$, bovine serum lauric acid/albumin hybrid-coated ferrofluid; vol, volume. 
MTO treatment, cells are blocked in the G2 phase to avoid proliferation of cells with modified DNA. The cell proliferation was affected accordingly by SEON ${ }^{\mathrm{LA}-\mathrm{BSA} * \text { MTO }}$ and pure MTO, whereas SEON ${ }^{\mathrm{LA}-\mathrm{BSA}}$ itself did not show any major effect (data not shown).

\section{Discussion}

\section{Synthesis and structural investigations}

Our work was dedicated to producing a core-shell SPION colloid which fulfills all the requirements for clinical use. We successfully synthesized SPIONs with a core size of $7.64 \pm 1.68 \mathrm{~nm}$ and coated them in situ with lauric acid forming a stable colloid. We then added a shell of BSA to those particles and investigated the colloidal properties, as well as the change of particle size and the zeta potential upon BSA addition. We found that the SEON ${ }^{\mathrm{LA}}$ particles were destabilized upon addition of low concentrations of BSA. Low protein concentrations of $0.5 \%$ and below lead to precipitation. At $1 \%$, the amount of protein was sufficient to form a stable colloid, but with a big aggregate size. With increasing protein amounts, the agglomerates became smaller and their size distribution became narrower. This critical dependence of the stability of such fatty acid/BSA hybrid-coated ferrofluids on the protein/SPION ratio has also been reported similarly by Zhang et al. ${ }^{25}$ Also, it was reported previously ${ }^{13}$ that such fatty acid-coated ferrofluids are stabilized by a bilayer of surfactant molecules, where the first layer is bound chemically and the second layer is adsorbed to the primary layer via carbonchain interaction. Thus, the presence of excess surfactant is a necessary condition for the stability of fatty acid-coated ferrofluids in aqueous media. As the adsorption of free lauric acid onto serum albumins is a well-known phenomenon, ${ }^{18}$ we believe that it is likely that lower amounts of BSA just bind free lauric acid while not or only partially stabilizing the particles on their own. This can lead to destabilization or precipitation of the colloid. At higher amounts, BSA itself becomes the main surface protecting agent and re-stabilizes the particles again. Above concentrations of 5\% of protein, the synthesis produced aggregates in narrow size distribution which lay within the previously defined, desirable range. In TEM images of the SEON ${ }^{\mathrm{LA}-\mathrm{BSA}}$ particles, an organic matrix in which the particle agglomerates were located was observed. We believed the matrix to consist of excess BSA and, possibly, remainders of lauric acid. To prove this hypothesis, we lyophilized the particles and investigated their chemical composition with FTIR. The results clearly demonstrated that the organic matrix mainly consisted of BSA. When looking at an unpurified sample with high BSA content, the fatty acid was masked almost entirely. Upon removal of the protein corona by ultrafiltration, however, it became visible again. This clearly indicates that the remaining lauric acid is located more at the particle cores than in the matrix, a finding that supports the proposed core-shell structure.

The zeta potential decreases drastically upon BSA addition, indicating the high stability of aqueous dispersions of SEON ${ }^{\text {LA-BSA }}$. As expected, the surface charge of the SEON ${ }^{\text {LA-BSA }}$ particles was $\mathrm{pH}$ dependent, with the point of zero charge being just below pH 5 which is very consistent with the isoelectric point of BSA. ${ }^{26}$ Around physiological $\mathrm{pH}$, however, the particles were still electrostatically stabilized, and even in more concentrated buffers we did not observe precipitation. The absolute zeta potential values, however, decreased considerably upon dilution of SEON ${ }^{\text {LA-BSA }}$ in those buffers. This could indicate a stabilization mechanism, which does not solely derive from electrostatic repulsion, but also from steric repulsion. When diluted in cell culture media, the size of SEON ${ }^{\mathrm{LA}}$ increases, whereas the size of SEON ${ }^{\mathrm{LA}-\mathrm{BSA}}$ decreases. This is consistent with the stability experiments, as they revealed that the latter is more stable and thus able to withstand complex media compounds. The zeta potential of both particle species decreases upon dilution in media, which we attribute to the surface adsorption of ionic substances and proteins.

\section{Stability assays and magnetic properties}

Finally, we investigated the stability of the particles in ethylenediaminetetraacetic acid-stabilized whole blood, and demonstrated a higher stability of SEON ${ }^{\mathrm{LA}-\mathrm{BSA}}$ as compared with SEON ${ }^{\mathrm{LA}}$. Also, the SEON ${ }^{\mathrm{LA}}$ particles caused deformation of the erythrocytes in their vicinity, an effect that shall be investigated in our future work. It was possible to visualize the SEON ${ }^{\mathrm{LA}-\mathrm{BSA}}$ particle clusters out of the blood plasma with TEM. These images confirmed that size and shape of the aggregates were unchanged after 24 hours of incubation.

It might be argued that such remarkably stable colloids are not well attractable by a magnet. However, we proved that even at dilutions of 1:100, it was possible to control the particles with a magnet, attract them, and redisperse them quickly. On this note, we also investigated the magnetic properties of the system in detail. Using SQUID measurements, we proved that the mean saturation magnetization of the particles is very close to the value for bulk magnetite $\mathrm{Fe}_{3} \mathrm{O}_{4}, M_{\text {s,bulk }}=475 \mathrm{kA} / \mathrm{m}$. It is also well above the value for bulk maghemite $\gamma-\mathrm{Fe}_{2} \mathrm{O}_{3}, M_{\text {s,bulk }} \approx 370 \mathrm{kA} / \mathrm{m}$ reported by Hunt et al. ${ }^{27}$ This is quite surprising, as the diameter of the particles is relatively small. But, as has been reported previously, ${ }^{28}$ performing the synthesis at $80^{\circ} \mathrm{C}$ and under 
Ar atmosphere favors the formation of the iron oxide with the higher magnetic saturation magnetization. Differences in the saturation magnetization during the VSM measurements could be attributed to minor deviations in the iron concentration measurements. However, when normalized on the volume percentage of magnetic material $\Phi$, the results are in good agreement with the results obtained by SQUID. To summarize, the magnetic characterizations revealed that the addition of BSA did not considerably affect the magnetic behavior of the system.

\section{In vitro evaluations of SEON ${ }^{L A}$ and SEON ${ }^{L A-B S A}$}

To investigate the biocompatibility of the hybrid-coated ferrofluids, their effect on primary endothelial cells was investigated. Endothelial cells are one of the first cell types that come in contact with the particles when they are injected into a blood vessel. The results showed that the treatment with $25 \mu \mathrm{g} / \mathrm{mL} 6 \% \mathrm{SEON}^{\mathrm{LA}-\mathrm{BSA}}$ was relatively well tolerated, with no observable effect after 24 hours after nanoparticle addition and somewhat decreased cell growth rates after 48-72 hours of treatment. Although this slower increase in cell-index indicated an inhibitory effect on cell proliferation, at this concentration of SEON ${ }^{\mathrm{LA}-\mathrm{BSA}}$ the cell-index was not reduced with time but steadily increased, indicating that HUVECs were viable and proliferating, albeit slower than untreated controls. Treatment with higher concentrations of SEON ${ }^{\mathrm{LA}-\mathrm{BSA}}$ $(50 \mu \mathrm{g} / \mathrm{mL}$ and $100 \mu \mathrm{g} / \mathrm{mL})$ led to a drastic decrease in cellindex already after 48 hours, indicative of cell death and detachment. HUVECs as primary cells are more sensitive to toxic effects than immortalized cell lines and thus enable more realistic predictions about the toxicity of substances in vivo. However, it should be noted that the applied particle concentrations (expressed as total iron concentrations) were about 250-fold higher than the ones of SEON ${ }^{\mathrm{LA}-\mathrm{BSA} * \text { MTO }}$ at which therapeutic effects were observed.

We also examined the effect of the BSA coating on the viability of the cells by flow cytometry. We compared the precursing SEON ${ }^{\mathrm{LA}}$ ferrofluid with the final SEON ${ }^{\mathrm{LA}-\mathrm{BSA}}$ product by investigating their effects on cell count, cellular morphology, mitochondrial membrane potential, phosphatidylserine exposure, plasma membrane integrity, and DNA content of human T-lymphoma cells. We found that both particle species are taken up by the cells, as shown by the increase in SSC. The uptake of SEON ${ }^{\mathrm{LA}}$ into the cells was significantly higher compared with SEON ${ }^{\text {LA-BSA }}$, an effect which we attribute to the different surface properties of the particles. Reduced uptake of particles by corona formation has been similarly reported by Lesniak et al. ${ }^{17}$ However, we did not measure significant differences in the surface charges of the two particle species in cell culture media. The particle sizes in cell culture media differed from each other. Particle size does have an influence on particle mobility and could also be influencing the results. ${ }^{29}$ Nonetheless, the uptake of SEON ${ }^{\text {LA-BSA }}$ particles was still sufficient to cause therapeutic effects when MTO was coupled to the particles. The overall number of cells was decreased compared with control by both particle species in a concentration-dependent way beginning at concentrations of $50\left(\mathrm{SEON}^{\mathrm{LA}}\right)$ or $75\left(\mathrm{SEON}^{\mathrm{LA}-\mathrm{BSA}}\right) \mu \mathrm{g} / \mathrm{mL}$. However, using AxA5/PI staining, PIT staining, and DiI staining, we proved that these effects are of different origin. Cells treated with high concentrations of SEON ${ }^{\text {LA-BSA }}$ still stay viable, whereas the cells treated with the same concentrations of SEON ${ }^{\mathrm{LA}}$ become apoptotic or necrotic and have their DNA degraded. From this, we conclude that the decrease in cell count after incubation with SEON ${ }^{\text {LA-BSA }}$ derives from hindered growth rather than from cell death. One may argue that the tested concentrations are rather high and that toxic concentrations might be caused by cellular overload. However, in MDT, a high amount of particles are attracted to a single spot, and indeed thus high concentrations are achieved. Also, it should be noted that SEON ${ }^{\text {LA-BSA }}$ did not induce cell death despite the high concentrations used.

\section{In vitro therapeutic potential and drug release of SEON ${ }^{L A-B S A * M T O}$}

To demonstrate the therapeutic potential of the particle system in vitro, we tested its suitability as a carrier system for drug delivery as just one example for a potential clinical application. ${ }^{14}$ The particles had a great loading capacity for the cytotoxic drug MTO, without losing their colloidal stability even at payloads of $300 \mu \mathrm{g} / \mathrm{mL}$ ferrofluid and higher. The drug binding mechanism is yet to be investigated. In our earlier work, we showed that MTO binds to lauric acid-coated iron oxide particles alone, ${ }^{14}$ but on the other hand, MTO does also exhibit high plasma protein binding. ${ }^{30}$ From the release kinetics, which was slow and linear over 72 hours and without any burst release, we rule out simple electrostatic interaction on the particle surface as binding mechanism. The drug was slowly released from the particle system with linear kinetics. From Fick's law, it follows that processes driven by diffusion follow a linear kinetics as long as the concentration gradient across the membrane is not greatly affected. We therefore conclude from our results that MTO is slowly diffusing out of the particle system. However, the resulting SEON ${ }^{\mathrm{LA}-\mathrm{BSA} * \mathrm{MTO}}$ particles exhibited drug dosedependent toxicity at time points, when over $95 \%$ of MTO is 
still bound on the particle system. Interestingly, we observed an increase in toxicity for the SEON ${ }^{\mathrm{LA}-\mathrm{BSA} * \mathrm{MTO}}$ as compared with free MTO. At the same time, we showed that the particles themselves were not toxic at the total iron concentrations used in these studies and that the amount of MTO inside viable cells is not enhanced by the coupling to the particles. This could indicate enhanced activity of the drug in its particle-coupled state and will be the subject of further investigations. With both free MTO and SEON ${ }^{\mathrm{LA}-\mathrm{BSA} * \text { MTO }}$, most of the cells whose DNA was not degraded were arrested in the G2 phase of the cell cycle, a phenomenon which is well known for this drug. ${ }^{31}$

\section{Conclusion and outlook}

From our data, we can conclude the following:

1. The described SEON ${ }^{\mathrm{LA}-\mathrm{BSA}}$ nanoparticle system has great potential for clinical applications as it exhibits both the desired physicochemical properties and a favorable in vitro biocompatibility profile.

2. The synthesis is well reproducible, straightforward, easily controllable, and suitable for the production of batches with higher volumes. The raw materials we used are cheap and easy to obtain in pharmaceutical quality. Thus, the synthesis process can be transferred into a good manufacturing practice-compliant environment.

3. The prepared nanosystem does not exhibit toxicity at moderate concentrations. It is colloidally stable and easily attractable with a magnet at the same time.

4. As a proof of concept, we tested the suitability of the SEON ${ }^{\text {LA-BSA }}$ nanoparticle system for MDT, showing its utility and efficacy.

5. Some aspects still need to be enlightened, such as the binding site of the drug, the release kinetics in biorelevant media as well as detailed ex vivo whole blood assays and, finally, in vivo toxicity. Also, for future application in humans, it may be necessary to use human serum albumin for immunological reasons.

These issues will be the topic of future investigations of ours.

\section{Acknowledgments}

This study was supported by the DFG (AL552/5-1, TR408/4-3, and OD18/23-1), the Else Kröner-Fresenius Stiftung (Bad Homburg v d H), the EU project FP7NMP-2012-LARGE-6-309820 "NanoAthero", the Bavarian Ministry for Environment and Consumer Protection (74-U8793-2012/7-35), the Cluster of Excellence Engineering of Advanced Materials (EAM), the ELAN-Fond, 10.03.02.1, and the Margarete Ammon Stiftung, Munich, Germany.
We also would like to thank Professor Beckmann (Department of Gynecology, University Hospital Erlangen, Germany) for providing umbilical cords and Professor Hermann (Department for Internal Medicine 3, University Hospital Erlangen, Germany) for providing AxA5-FITC. We also acknowledge support by DFG and Friedrich-Alexander-Universität Erlangen-Nürnberg (FAU) within the funding program Open Access Publishing.

\section{Disclosure}

The authors report no conflicts of interest in this work.

\section{References}

1. Gupta AK, Gupta M. Synthesis and surface engineering of iron oxide nanoparticles for biomedical applications. Biomaterials. 2005;26(18):3995-4021.

2. Wadajkar AS, Menon JU, Kadapure T, Tran RT, Yang J, Nguyen KT. Design and application of magnetic-based theranostic nanoparticle systems. Recent Pat Biomed Eng. 2013;6(1):47-57.

3. Lu AH, Salabas EL, Schuth F. Magnetic nanoparticles: synthesis, protection, functionalization, and application. Angew Chem Int Ed Engl. 2007;46(8):1222-1244.

4. Tóth IY, Illés E, Bauer RA, et al. Designed polyelectrolyte shell on magnetite nanocore for dilution-resistant biocompatible magnetic fluids. Langmuir. 2012;28(48):16638-16646.

5. Albanese A, Tang PS, Chan WC. The effect of nanoparticle size, shape, and surface chemistry on biological systems. Annu Rev Biomed Eng. 2012;14:1-16.

6. Sharma A, Madhunapantula SV, Robertson GP. Toxicological considerations when creating nanoparticle-based drugs and drug delivery systems. Expert Opin Drug Metab Toxicol. 2012;8(1):47-69.

7. Hanini A, Schmitt A, Kacem K, Chau F, Ammar S, Gavard J. Evaluation of iron oxide nanoparticle biocompatibility. Int J Nanomedicine. 2011;6:787-794.

8. Zauner W, Farrow NA, Haines AM. In vitro uptake of polystyrene microspheres: effect of particle size, cell line and cell density. J Control Release. 2001;71(1):39-51.

9. Sun Z, Yathindranath V, Worden M, et al. Characterization of cellular uptake and toxicity of aminosilane-coated iron oxide nanoparticles with different charges in central nervous system-relevant cell culture models. Int J Nanomedicine. 2013;8:961-970.

10. Hang J, Shi L, Feng X, Xiao L. Electrostatic and electrosteric stabilization of aqueous suspensions of barite nanoparticles. Powder Technol. 2009;192(2):166-170.

11. Verwey E, Overbeek J. Theory of the Stability of Lyophobic Colloids. Amsterdam: Elsevier; 1948.

12. Bica D, Vékás L, Avdeev MV, et al. Sterically stabilized water based magnetic fluids: synthesis, structure and properties. J Magn Magn Mater. 2007;311(1):17-21.

13. Shen L, Laibinis PE, Hatton TA. Bilayer surfactant stabilized magnetic fluids: synthesis and interactions at interfaces. Langmuir. 1998;15(2):447-453.

14. Tietze R, Lyer S, Dürr S, et al. Efficient drug-delivery using magnetic nanoparticles - biodistribution and therapeutic effects in tumour bearing rabbits. Nanomedicine. 2013;9(7):961-971.

15. Alexiou C, Jurgons R, Schmid RJ, et al. Magnetic drug targeting biodistribution of the magnetic carrier and the chemotherapeutic agent mitoxantrone after locoregional cancer treatment. J Drug Target. 2003;11(3):139-149.

16. Gebauer JS, Malissek M, Simon S, et al. Impact of the nanoparticleprotein corona on colloidal stability and protein structure. Langmuir. 2012;28(25):9673-9679. 
17. Lesniak A, Fenaroli F, Monopoli MP, Åberg C, Dawson KA, Salvati A. Effects of the presence or absence of a protein corona on silica nanoparticle uptake and impact on cells. ACS Nano. 2012;6(7):5845-5857.

18. Goodman DS. The interaction of human serum albumin with long-chain fatty acid anions. J Am Chem Soc. 1958;80(15):3892-3898.

19. Dokuzovic D. Kolorimetrie-Photometrie [Colorimetry-Photometry]. [webpage available on the Internet]. Available from: http://www.lickl. net/doku/photo.pdf. Accessed June 8, 2014. German.

20. Tietze R, Schreiber E, Lyer S, Alexiou C. Mitoxantrone loaded superparamagnetic nanoparticles for drug targeting: a versatile and sensitive method for quantification of drug enrichment in rabbit tissues using HPLC-UV. J Biomed Biotechnol. 2010;2010:597304.

21. Kroll A, Pillukat MH, Hahn D, Schnekenburger J. Interference of engineered nanoparticles with in vitro toxicity assays. Arch Toxicol. 2012;86(7):1123-1136.

22. Munoz LE, Maueroder C, Chaurio R, Berens C, Herrmann M, Janko C. Colourful death: six-parameter classification of cell death by flow cytometry - dead cells tell tales. Autoimmunity. 2013;46(5):336-341.

23. Nicoletti I, Migliorati G, Pagliacci MC, Grignani F, Riccardi C. A rapid and simple method for measuring thymocyte apoptosis by propidium iodide staining and flow cytometry. J Immunol Methods. 1991;139(2):271-279.

24. Zucker RM, Daniel KM. Detection of $\mathrm{TiO}_{2}$ nanoparticles in cells by flow cytometry. Methods Mol Biol. 2012;906:497-509.
25. Zhang B, Li Q, Yin P, et al. Ultrasound-triggered BSA/SPION hybrid nanoclusters for liver-specific magnetic resonance imaging. ACS Appl Mater Interfaces. 2012;4(12):6479-6486.

26. Salgin S, Salgin U, Bahadir S. Zeta potentials and isoelectric points of biomolecules: the effects of ion types and ionic strengths. Int J Electrochem Sci. 2012;7(12):12404-12414.

27. Hunt CP, Singer MJ, Kletetschka G, TenPas J, Verosub KL. Effect of citrate-bicarbonate-dithionite treatment on fine-grained magnetite and maghemite. Earth Planet Sc Lett. 1995;130(1-4):87-94.

28. Zhang L, Papaefthymiou GC, Ying JY. Size quantization and interfacial effects on a novel $\gamma-\mathrm{Fe}_{2} \mathrm{O}_{3} / \mathrm{SiO}_{2}$ magnetic nanocomposite via sol-gel matrix-mediated synthesis. J Appl Phys. 1997;81(10):6892-6900.

29. Hinderliter PM, Minard KR, Orr G, et al. ISDD: a computational model of particle sedimentation, diffusion and target cell dosimetry for in vitro toxicity studies. Part Fibre Toxicol. 2010;7(1):36.

30. Faulds D, Balfour J, Chrisp P, Langtry H. Mitoxantrone. Drugs. 1991; 41(3):400-449.

31. Asamura M, Yokoyama M, Kanamaru R, et al. [In vivo antitumor activity of mitoxantrone and the flow cytometric analysis of its influence on cell cycle transition - comparison with doxorubicin and aclarubicin on ascitic hepatoma AH109A cells]. Gan to Kagaku Ryoho. 1989;16(12):3769-3776. Japanese. 


\section{Supplementary materials}

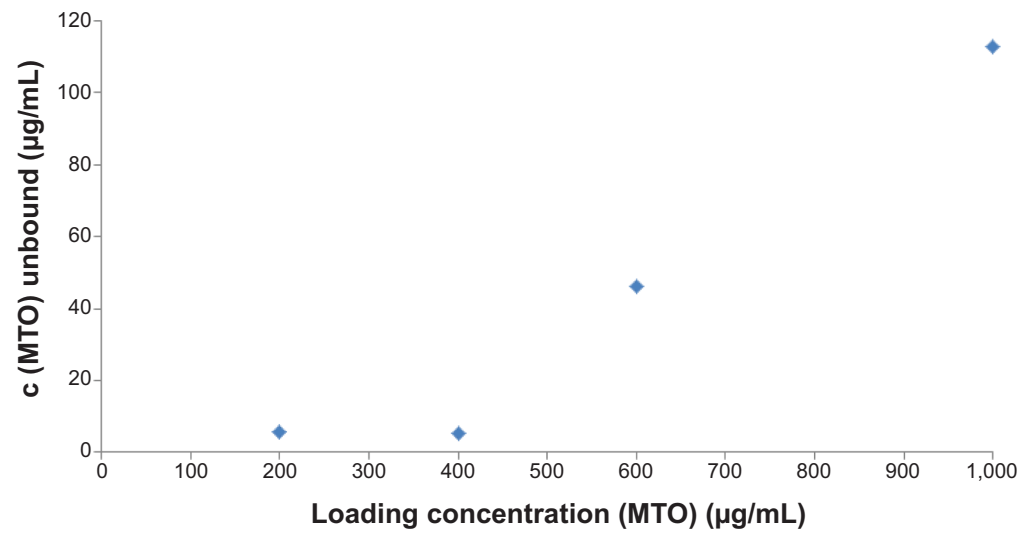

Figure SI Concentration of free MTO after binding to $6 \%$ SEON ${ }^{\text {LA-BSA. }}$.

Notes: The amount of free MTO increases in a linear way above a payload of $400 \mu \mathrm{g} \mathrm{MTO} / \mathrm{mL}$ ferrofluid. All measurements were performed in triplicate. Abbreviations: MTO, mitoxantrone; SEON ${ }^{\text {LA-BSA }}$, bovine serum lauric acid/albumin hybrid-coated ferrofluid.

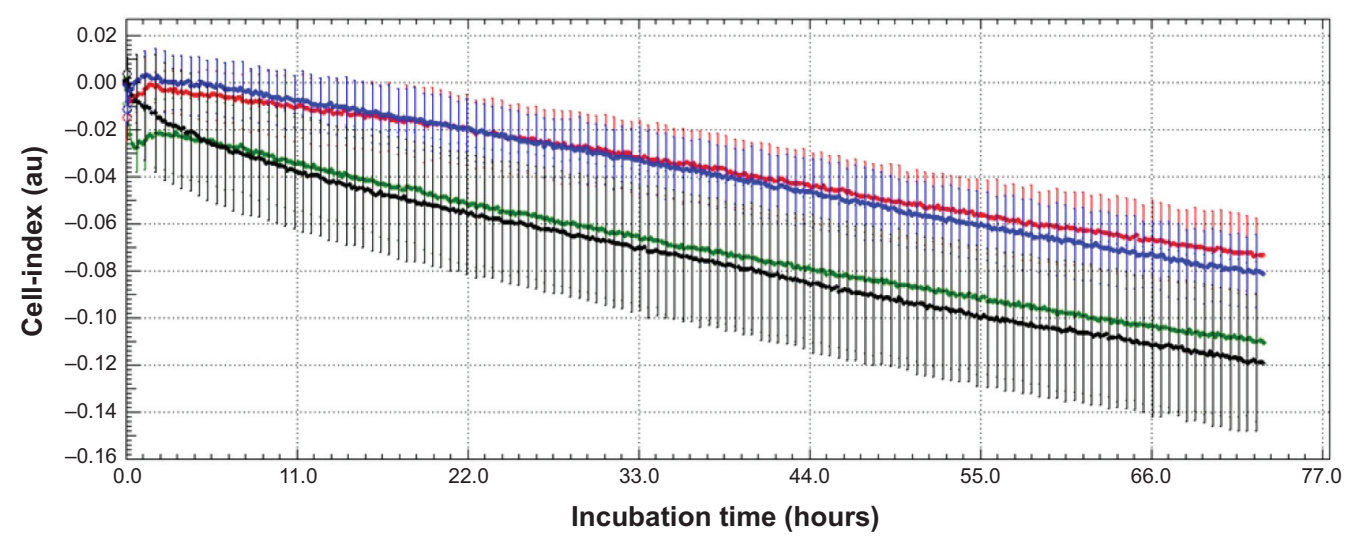

Figure $\mathbf{S 2}$ Control impedance measurement for particle suspensions.

Notes: No significant change in the impedance was detected for I $\mu \mathrm{g} / \mathrm{mL}$ (red), $10 \mu \mathrm{g} / \mathrm{mL}$ (blue) and $100 \mu g / \mathrm{mL}$ (black) compared to control without particles (green). All measurements were performed in quintuplicate.

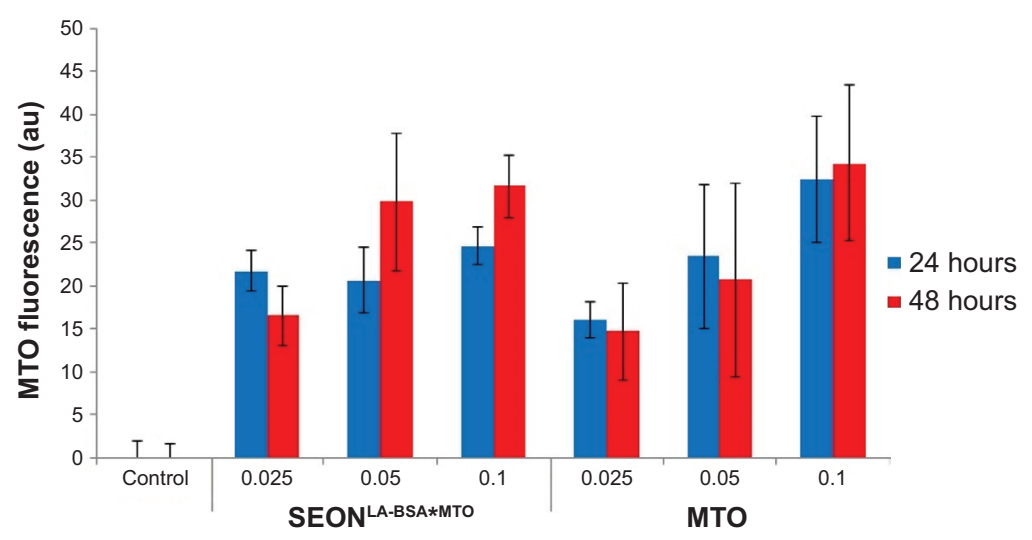

Figure S3 MTO fluorescence measurements in viable cells after 24 and 48 hours of incubation with free MTO or SEONLA-BSA*MTO at different concentrations. Notes: No significant difference was observed between free MTO or SEONLA-BSA*MTO. The values are relative to controls ( $\mathrm{n}=3$ ). All concentrations are given in micrograms per milliliter.

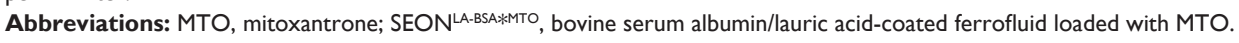


Video SI Video of $100 \mu \mathrm{L}$ SEON ${ }^{\text {LA-BSA }}$ injected into $2 \mathrm{~mL}$ of water.

Notes: When the magnetic field is turned on (field strength $=140 \mathrm{mT}$ ), the particle suspension as a whole is attracted to the magnet. When the magnet is turned off, the suspension sediments due to gravity.

Abbreviation: SEON ${ }^{L A-B S A}$, bovine serum lauric acid/albumin hybrid-coated ferrofluid.

\section{Publish your work in this journal}

The International Journal of Nanomedicine is an international, peerreviewed journal focusing on the application of nanotechnology in diagnostics, therapeutics, and drug delivery systems throughout the biomedical field. This journal is indexed on PubMed Central,

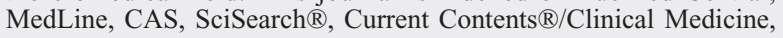

Journal Citation Reports/Science Edition, EMBase, Scopus and the Elsevier Bibliographic databases. The manuscript management system is completely online and includes a very quick and fair peer-review system, which is all easy to use. Visit http://www.dovepress.com/ testimonials.php to read real quotes from published authors.

Submit your manuscript here: http://www.dovepress.com/international-journal-of-nanomedicine-journal 